\title{
Impact of isolated atmospheric aging processes on the cloud condensation nuclei activation of soot particles
}

\author{
Franz Friebel $^{1}$, Prem Lobo ${ }^{1,2, a}$, David Neubauer ${ }^{1}$, Ulrike Lohmann ${ }^{1}$, Saskia Drossaart van Dusseldorp ${ }^{1}$, \\ Evelyn Mühlhofer ${ }^{1}$, and Amewu A. Mensah ${ }^{1, b}$ \\ ${ }^{1}$ Institute for Atmospheric and Climate Science, ETH Zurich, Zurich, 8092, Switzerland \\ ${ }^{2}$ Center of Excellence for Aerospace Particulate Emissions Reduction Research, Missouri University of \\ Science and Technology, Rolla, Missouri 65401, USA \\ ${ }^{a}$ now at: Metrology Research Centre, National Research Council Canada, Ottawa, Ontario K1A 0R6, Canada \\ bnow at: Environmental and Health Protection Service, City of Zurich, Zurich, 8003, Switzerland
}

Correspondence: Franz Friebel (franz.friebel@env.ethz.ch) and Amewu A. Mensah (a.mensah@alumni.ethz.ch)

Received: 28 May 2019 - Discussion started: 27 June 2019

Revised: 16 October 2019 - Accepted: 9 November 2019 - Published: 19 December 2019

\begin{abstract}
The largest contributors to the uncertainty in assessing the anthropogenic contribution in radiative forcing are the direct and indirect effects of aerosol particles on the Earth's radiative budget. Soot particles are of special interest since their properties can change significantly due to aging processes once they are emitted into the atmosphere. Probably the largest obstacle for the investigation of these processes in the laboratory is the long atmospheric lifetime of 1 week, requiring tailored experiments that cover this time span. This work presents results on the ability of two types of soot, obtained using a miniCAST soot generator, to act as cloud condensation nuclei $(\mathrm{CCN})$ after exposure to atmospherically relevant levels of ozone $\left(\mathrm{O}_{3}\right)$ and humidity. Aging times of up to $12 \mathrm{~h}$ were achieved by successful application of the continuous-flow stirred tank reactor (CSTR) concept while allowing for size selection of particles prior to the aging step. Particles of $100 \mathrm{~nm}$ diameter and rich in organic carbon (OC) that were initially $\mathrm{CCN}$ inactive showed significant $\mathrm{CCN}$ activity at supersaturations (SS) down to $0.3 \%$ after $10 \mathrm{~h}$ of exposure to $200 \mathrm{ppb}$ of $\mathrm{O}_{3}$. While this process was not affected by different levels of relative humidity in the range of $5 \%-75 \%$, a high sensitivity towards the ambient/reaction temperature was observed. Soot particles with a lower OC content required an approximately 4 -fold longer aging duration to show CCN activity at the same SS. Prior to the slow change in the $\mathrm{CCN}$ activity, a rapid increase in the particle diameter was detected which occurred within several minutes. This study highlights the applicability of the CSTR
\end{abstract}

approach for the simulation of atmospheric aging processes, as aging durations beyond $12 \mathrm{~h}$ can be achieved in comparably small aerosol chamber volumes $\left(<3 \mathrm{~m}^{3}\right)$. Implementation of our measurement results in a global aerosol-climate model, ECHAM6.3-HAM2.3, showed a statistically significant increase in the regional and global CCN burden and cloud droplet number concentration.

\section{Introduction}

Aerosols are defined as fine solid particles or liquid droplets suspended in a gas phase. Aerosol particles impact the Earth's radiative budget both directly (e.g., through scattering of shortwave and absorption of shortwave and longwave radiation) (Haywood and Boucher, 2000) and indirectly (e.g., by changing the properties of clouds; Ackerman et al., 2000; Lohmann and Feichter, 2005; Seinfeld et al., 2016; Twomey, 1977). Furthermore, they demonstrate significant impacts on air quality and human health (Anenberg et al., 2012; Janssen et al., 2011). The chemical and physical properties of atmospheric aerosol particles are highly variable and depend on surface (land versus ocean), region (urban versus remote), source (anthropogenic versus biogenic), and many more aspects. Additionally, ambient aerosol particles undergo physicochemical modification processes throughout their atmospheric lifetime (Monks et al., 2009). Condensation of gas-phase volatile material or heterogeneous oxida- 
tion are general examples of these processes that are referred to as aging. An example of the multiple ways these processes modify the physicochemical properties of the particles is the change in the water affinity of an initially hydrophobic particle. Accumulation of hygroscopic material on the surface can cause such a particle to become hydrophilic (Dalirian et al., 2018; Henning et al., 2012; Khalizov et al., 2009). Depending on the surrounding conditions, the particle can accumulate water vapor and form a droplet as in a cloud or in fog.

The process of forming a cloud droplet is called cloud droplet activation and the respective particles are called cloud condensation nuclei (CCN). The particle's ability to act as CCN depends on its properties, such as size, morphology, and chemical composition (Köhler, 1936; Sorjamaa and Laaksonen, 2007). While particles consisting of hygroscopic compounds such as sea salt have a high CCN activity, other particles such as soot (also referred to as black carbon, BC) show extremely low CCN activity (Petzold et al., 2013). Nevertheless, BC particles have been found in cloud droplet and ice crystal residuals in ambient measurements, indicating that within their atmospheric lifetime these particles are incorporated into hydrometeors (Cozic et al., 2008; Hiranuma et al., 2013).

Soot is a by-product of incomplete combustion. Depending on its origin, soot varies greatly in chemical composition, size, and co-emitted substances. Soot particles have an atmospheric lifetime of up to 1 week, which is long compared to other aerosol particles (Textor et al., 2006). Currently, the impact of soot particles on human health, environment, and climate is of scientific and economic interest. Understanding their carcinogenic nature (WHO, 2016) or their impact on crops (Burney and Ramanathan, 2014) is only one example of the increased interest in soot particles during the last few decades. Regarding their atmospheric impact, good understanding has been gained with respect to their direct effect on visibility and air quality, but their indirect climate impact, i.e., on clouds and cloud formation, remains highly uncertain (IPCC, 2013).

The pathway of how soot particles end up in hydrometeor residuals remains a major topic of discussion. On the one hand, these hydrophobic particles show little interaction with water and are reported to be poor CCN and ice-nucleating particles, respectively (INPs; Friedman et al., 2011; Koehler et al., 2009; Kulkarni et al., 2016). On the other hand, field measurements show that soot particles are enriched in cloud droplets and ice crystals compared to interstitial particles (Cozic et al., 2008; Hiranuma et al., 2013). These findings indicate that soot particles can become incorporated into hydrometeors beyond impaction scavenging potentially by an increase in hygroscopicity upon atmospheric aging turning them into CCN or INPs, respectively. The details and relevance of atmospheric aging processes potentially causing such a significant change in CCN activity of soot particles are not well understood yet. Besides the complexity of aerosol particles, one of the challenges lies in investigating these processes in the laboratory at atmospheric conditions. Furthermore, modeling studies show that even though soot particles are poor INPs compared to dust particles (Kanji et al., 2017), they are still relevant INPs in the atmosphere due to their high abundance (Hoose et al., 2010; Savre and Ekman, 2015).

While there is a broad consensus that coating with hygroscopic substances, e.g., sulfuric acid (Dalirian et al., 2018; Henning et al., 2012; Khalizov et al., 2009), increases the particle-water interaction of soot particles, the influence of oxidation processes is less well understood. The impact of oxidation processes can be investigated by simulating atmospheric aging under controlled laboratory conditions. One of the experimental challenges is to achieve extended aging time periods because the average atmospheric lifetime of soot particles is approximately 1 week (Textor et al., 2006). A common approach is the application of (photo-)oxidation flow reactors (OFRs) like the Potential Aerosol Mass (PAM) chamber (Kang et al., 2007), the Toronto Photo-Oxidation Tube (TPOT; George et al., 2007), the Micro Smog Chamber (MSC; Keller and Burtscher, 2012), the TUT Secondary Aerosol Reactor (TSAR; Simonen et al., 2017) or the Photochemical Emission Aging flow tube Reactor (PEAR; Ihalainen et al., 2019). Within these devices, the residence time ranges from 3 to $170 \mathrm{~s}$ and the $\mathrm{OH}$-radical concentration ranges from $4.9 \times 10^{8}$ to $130 \times 10^{8} \mathrm{molec} \mathrm{cm}^{-3}$, while the average atmospheric $\mathrm{OH}$-radical concentration is orders of magnitude lower with $1.5 \times 10^{6} \mathrm{molec}^{-3}$ (Mao et al., 2009). The exposure conditions are recalculated to an equivalent atmospheric aging time of 0.4 to $10 \mathrm{~d}$ (Lambe et al., 2015). This approach implies that the oxidation speed is linearly dependent on the concentration of $\mathrm{OH}$ radicals, which is supported by the findings of Bedjanian et al. (2010). Deploying larger aerosol chambers with several cubic meters of volume operated in batch mode allows for longer experimental durations at more atmospherically relevant oxidant concentration levels. For example, Wittbom et al. (2014) achieved aging durations of up to $5 \mathrm{~h}$ in a $6 \mathrm{~m}^{3}$ aerosol chamber at $\mathrm{OH}$-radical concentrations ranging from $1 \times 10^{6}$ to $2 \times 10^{6}$ molec $\mathrm{cm}^{-3}$, which is approximately equal to $1 \mathrm{~d}$ of atmospheric aging. Both the OFRs and the batch-aerosol chamber methods show that equivalent atmospheric aging time spans of several hours to days are required to make soot particles $\mathrm{CCN}$-active at atmospherically relevant supersaturations (SSs) of below $0.8 \%$ (Pruppacher and Klett, 2010).

Another very important atmospheric oxidant is ozone $\left(\mathrm{O}_{3}\right)$. The effect of $\mathrm{O}_{3}$ oxidation on the CCN activity of soot particles has been investigated extensively in various laboratory studies. Despite these efforts, no $\mathrm{CCN}$ activation at atmospheric $\mathrm{O}_{3}$ concentration and atmospherically relevant SS has been reported to the authors' knowledge. However, in the range from 1200 to $20000 \mathrm{ppb}_{3}$ a significant increase in CCN activity of soot particles was reported for SS above $0.8 \%$ for exposure times between $100 \mathrm{~s}$ and $2 \mathrm{~h}$, which should correspond to atmospheric aging times of up to $3.5 \mathrm{~d}$ 
(Friedman et al., 2011; Grimonprez et al., 2018; Lambe et al., 2015). In contrast to the agreement regarding the linearity of aging and $\mathrm{OH}$ exposure within the scientific community (Renbaum and Smith, 2011), there is no such consensus concerning aging and $\mathrm{O}_{3}$ exposure. While the results of the studies mentioned above are interpreted on the assumption that the oxidation speed is directly proportional to the $\mathrm{O}_{3}$ concentration, Kotzick et al. (1997) reported that no impact of concentration could be detected in the range from 25 to $1000 \mathrm{ppb} \mathrm{O}_{3}$.

Studies focusing on the uptake of $\mathrm{O}_{3}$ by soot particles suggest that the reaction might not follow first-order kinetics with respect to the $\mathrm{O}_{3}$ gas-phase concentration (e.g., Ammann et al., 2003; Kamm et al., 1999; Lelievre et al., 2004; McCabe and Abbatt, 2009; Zelenay et al., 2011). Similar results have been found for the decomposition of polycyclic aromatic hydrocarbons (PAHs) and other organic compounds condensed on aerosol particle surfaces (Bedjanian and Nguyen, 2010; McNeill et al., 2007; Pöschl et al., 2001; Shiraiwa et al., 2011). These findings combined with soot particles found in hydrometeor residuals question the validity of extrapolations from non-atmospheric reaction conditions being used as the basis to infer atmospheric implications. To evaluate the atmospheric relevance of $\mathrm{O}_{3}$ oxidation for the CCN activity of soot particles and the impact of the $\mathrm{O}_{3}$ concentration in the atmospherically relevant range, laboratory experiments should preferably be performed at atmospherically relevant conditions with respect to oxidant concentration, relative humidity $(\mathrm{RH})$, particle number concentration as well as reaction time.

Different experimental setups provide different advantages with respect to mimicking atmospheric aging processes. OFRs have the advantage of operating at particle number concentrations prevalent in the atmosphere. Therefore, the aerosol particles can be size-selected before entering the chamber, and changes in the $\mathrm{CCN}$ activity can be investigated excluding artifacts from potential size-related effects, however, because those chambers are operated at oxidant conditions that are up to 4 orders of magnitude higher than in the atmosphere (Bruns et al., 2015) and might follow atmospherically non-relevant reaction pathways (McNeill et al., 2007). In contrast to the OFRs, there are large aerosol chambers with several $\mathrm{m}^{3}$ of volume in which aerosols can be exposed to atmospherically relevant concentrations of oxidants and trace gases (Cocker et al., 2001; Leskinen et al., 2015; Nordin et al., 2013; Paulsen et al., 2005; Platt et al., 2013; Presto et al., 2005; Rohrer et al., 2005). Because those chambers are typically operated in batch mode, they require elevated particle number concentrations in the input flow in order to reach the desired aerosol concentration inside the chamber within a reasonable time. Therefore, these types of chambers are often filled with non-size-selected aerosol particles, hampering the separation of CCN activation due to chemical transformation from potential particle size effects.
In this paper, we present the results from a study investigating the effect of heterogeneous $\mathrm{O}_{3}$ oxidation at atmospherically relevant conditions on the $\mathrm{CCN}$ activity of soot particles derived from a co-flow propane diffusion flame. The experiments were performed within a $\sim 3 \mathrm{~m}^{3}$ stainless steel aerosol chamber operated in continuous-flow stirred tank reactor (CSTR) mode. This approach allowed us to (1) achieve aging durations of up to $12 \mathrm{~h},(2)$ utilize atmospherically relevant $\mathrm{O}_{3}$ concentrations of up to $200 \mathrm{ppb}$ and varying levels of humidity, and (3) execute the experiments with $100 \mathrm{~nm}$ size-selected soot particles. The experimental results were then implemented in the ECHAM6.3-HAM2.3 global climate model (Neubauer et al., 2019; Tegen et al., 2019). Based on these results, we discuss the impact of aging processes on the change in $\mathrm{CCN}$ burden and cloud droplet number concentration (CDNC) on the global as well as regional scale.

\section{Experimental setup}

\subsection{Overview}

Multiple sets of experiments were performed in the laboratory using a $2.78 \mathrm{~m}^{3}$ stainless steel aerosol chamber at ETH Zurich, Switzerland, during summer 2016 and summer 2018. A schematic of the experimental setup is shown in Fig. 1. To allow for extended aging durations of up to $12 \mathrm{~h}$, the aerosol chamber was operated following the concept of the CSTR (Levenspiel, 1999). In accordance with this concept, soot particles were continuously added to the aerosol chamber inlet, simultaneous to the continuous withdrawal of aerosol samples from the chamber outlet for analysis. All sample lines used within the setup consisted of stainless steel with an inner diameter of $4 \mathrm{~mm}$. The sample lines were configured such that the soot aerosol could be sampled either directly upstream, i.e., bypassing, or downstream of the aerosol chamber. Friebel and Mensah (2019) introduced a new analysis technique that allows for the retrieval of $\mathrm{CCN}$ activation data from experiments executed in aerosol chambers operated in CSTR mode. In addition to the investigation of the $\mathrm{CCN}$ activity, data were recorded for the investigation of a broad range of physical and chemical parameters, e.g., the size and mass distribution of the particles, the INP potential, the chemical composition, and the lung deposited surface area (LDSA). Further details on the experimental setup, instrumentation, and specific settings beyond the information given in the following section can be found in the Appendix.

Soot particles were produced by a propane-fueled Jing Ltd., miniature Combustion Aerosol STandard (miniCAST 4200) generator. Such types of burners and specifically the miniCAST burner have been used widely for the production of soot particles in laboratory studies (e.g., Durdina et al., 2016; Kim et al., 2015; Malmborg et al., 2018; Mamakos et al., 2013; Maricq, 2014; Mueller et al., 2015; Török et al., 2018). The miniCAST was operated at two different settings 


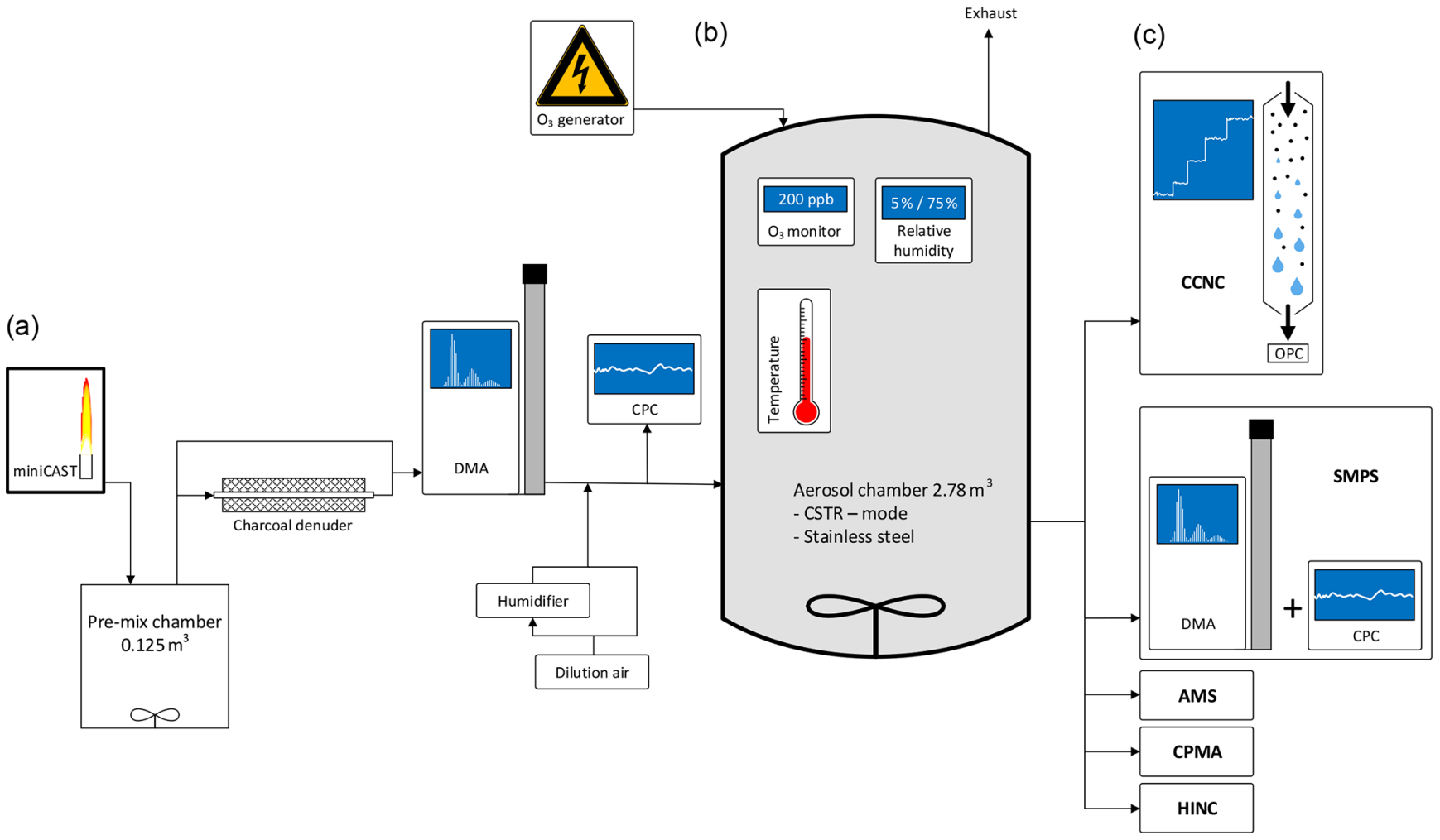

Figure 1. Schematic of the experimental setup. Indicated are aerosol production and conditioning (a), the aging chamber (b), and the characterization instruments (c).

for the generation of soot samples with different organic carbon (OC) contents. The first sample, hereafter referred to as CAST brown (CBW), was generated under fuel-rich conditions (fuel-air ratio; FAR $=1.03$ ). The second sample, hereafter referred to as CAST black (CBK), was generated under fuel-lean conditions (FAR $=0.95)$. Further details on the miniCAST set points used during the study are listed in Appendix Table A1.

The miniCAST has been used as a surrogate for soot emissions from vehicle internal combustion engines (Maricq, 2014; Moore et al., 2014; Mueller et al., 2015) and aircraft engines (Bescond et al., 2014; Durdina et al., 2016). According to Marhaba et al. (2019), high engine thrust levels can be mimicked by CBK soot, while CBW soot better represents engine emissions at lower thrust levels.

The gases used were nitrogen $\left(\mathrm{N}_{2}\right)$ of grade 6.0 for mixing and quenching and in-house filtered and compressed air for oxidation and dilution. The compressed air was purified by passing through a particle filter, resulting in a particle concentration below the detection limit of the particle counting instrumentation. The air was further passed through a charcoal filter for the removal of volatile organic compounds (VOCs). The remaining VOC content was tested by mixing the filtered air with $200 \mathrm{ppb}$ of $\mathrm{O}_{3}$. As no new particle formation could be detected, we considered the filtered air particleand VOC-free with respect to our instrumentation.
After starting the burner, it was run for at least $2 \mathrm{~h}$ before the operating conditions were considered stable and the output was sampled. The output of the miniCAST burner was diluted by a factor of 10 using a Palas VKL 10 diluter; $6 \mathrm{~L} \mathrm{~min}^{-1}$ of the diluted sample was introduced into a premix chamber of $0.125 \mathrm{~m}^{3}$ volume. The stainless steel premix chamber was air-tight and equipped with a continuously stirring fan. To allow for the selection of $100 \mathrm{~nm}$ particles of sufficient concentration, the particles were allowed to agglomerate within the pre-mix chamber. After an average residence time of $21 \mathrm{~min}$, the mode diameter of CBW and CBK particles was 90 and $150 \mathrm{~nm}$, respectively.

\subsection{Aerosol chamber}

A $2.78 \mathrm{~m}^{3}$ stainless steel aerosol chamber was used as a reaction vessel. As a detailed description of the stainless steel aerosol chamber has been previously presented by Kanji et al. (2013), only a brief description follows. The aerosol chamber is equipped with a pitched blade fan of $30 \mathrm{~cm}$ diameter at its bottom. The fan was operated at $1000 \mathrm{rpm}$ to ensure a homogenous distribution of the aerosol throughout the aerosol chamber. Based on the operational experience acquired in summer 2016, the aluminum fan was gold-plated prior to the campaign in summer 2018 to increase its conductivity and thereby reduce particle loss on its surface. Tem- 
perature, pressure, and $\mathrm{RH}$ inside the aerosol chamber were monitored by sensors mounted on a diagonally oriented taut wire. While pressure and RH were controlled by the conditions of the input flow, the double-wall design of the aerosol chamber allowed for direct temperature control, which was utilized in some of the experiments. Soot aerosol and $\mathrm{O}_{3}$ were introduced through individual ports on the stainless steel aerosol chamber. Another port was used for the withdrawal of sample aerosol, which then was distributed to various measurement instruments.

In general, the total volumetric flow through the aerosol chamber during filling and steady state was set to $23 \mathrm{~L} \mathrm{~min}^{-1}$. In some experiments, a reduced flow rate of $13 \mathrm{~L} \mathrm{~min}^{-1}$ was applied during the overnight flushing regime to maximize the duration of particle concentration above the detection limit. The experimental conditions allowed the exposure time of the soot aerosol during oxidation and humidification experiments to be extended up to $12 \mathrm{~h}$.

\subsection{Sample selection and conditioning}

The soot aerosol was conditioned in multiple ways prior to entering as well as within the aerosol chamber. Following the pre-mix chamber, a home-built charcoal denuder was placed in-line for the removal of remaining gas-phase VOCs from the combustion process within the miniCAST burner. The denuder consisted of a glass tube of $40 \mathrm{~cm}$ in length and $10 \mathrm{~cm}$ in diameter filled with approximately $0.7 \mathrm{~kg}$ of activated charcoal (Sigma-Aldrich). A metal mesh of $1.5 \mathrm{~cm}$ diameter connecting the inlet and outlet of the denuder allowed the aerosol stream to pass through the center of the denuder without direct exposure to the charcoal. The denuder was bypassed (i.e., the sample was not denuded) for some of the experiments to evaluate the potential impact of the remaining VOCs on the CCN activity of the particles. A TSI 3081L Differential Mobility Analyzer (DMA) was used downstream of the denuder for the selection of $100 \mathrm{~nm}$ soot particles. The DMA was operated with a sample airflow rate of 1.7 to $1.9 \mathrm{~L} \mathrm{~min}^{-1}$ and a sheath airflow rate of $10 \mathrm{~L} \mathrm{~min}^{-1}$. After diluting the sample airflow with $21 \mathrm{~L} \mathrm{~min}^{-1}$ of particleand VOC-free compressed air, a particle concentration of $\sim 1200 \mathrm{~cm}^{-3}$ was achieved. A TSI 3772 Condensation Particle Counter (CPC) was used to monitor the number concentration of the soot aerosol particles entering the aerosol chamber. The input concentration remained stable for the entire duration of an experimental run.

Conditioning of the soot particles with $\mathrm{O}_{3}$ or elevated humidity took place within the aerosol chamber. Gas streams containing $\mathrm{O}_{3}$ and water vapor were fed into the aerosol chamber through individual ports. $\mathrm{O}_{3}$ was produced by a continuously running corona discharge $\mathrm{O}_{3}$ tube operating on high-purity 5.6 synthetic air. The output of the $\mathrm{O}_{3}$ generator was diluted by a factor of 100 using a Palas VKL 100 diluter with particle- and VOC-free in-house compressed air. The flow rate of the $\mathrm{O}_{3}$ stream into the stainless steel aerosol chamber was maintained at $0.040-0.070 \mathrm{Lmin}^{-1}$. The $\mathrm{O}_{3}$ concentration within the aerosol chamber was monitored by an Aeroqual series 940 transmitter (0-0.5 ppm) mounted on an additional port. For sample humidification, particle- and VOC-free compressed air was split into multiple streams. One stream was passed through a silica gel diffusion dryer, resulting in a $\mathrm{RH}$ of less than $5 \%$. The second stream was split and led through two Nafion-humidifier coil tubes surrounded by thermostated water, resulting in a $\mathrm{RH}$ of up to $95 \%$. The temperature of the water was controlled by using an Ecoline Immersion thermostat E300 with stainless steel bath 006. The flow rates of the dry and the humidified air streams were regulated by individual mass flow controllers (MKS, 0-20 $\mathrm{L} \mathrm{min}^{-1}$ ) and mixed within a $5 \mathrm{~L}$ glass volume. This setup allowed for the stable production of air at a preset RH level and a flow rate of $20 \mathrm{~L} \mathrm{~min}^{-1}$. In addition to the sensors monitoring the humidity within the aerosol chamber, a Vaisala HMT337 humidity sensor was used to monitor the humidification air before entering the aerosol chamber.

\subsection{Sample characterization}

A suite of instruments was deployed for the characterization of the soot particle samples. Besides stationary center pieces for the determination of the particle size distribution and $\mathrm{CCN}$ activity, the specific configuration of instruments varied depending on availability. Data on the chemical composition, the INP activity, and the single-particle mass were acquired in many but not all experiments.

A TSI Scanning Mobility Particle Sizer (SMPS) consisting of a TSI 3081L DMA and a TSI 3772 CPC was used to record the particle size distributions in the range of $8-280 \mathrm{~nm}$ at a scanning frequency of $135 \mathrm{~s}$. The DMA was operated with a sample flow rate of $1 \mathrm{~L} \mathrm{~min}^{-1}$ and a sheath airflow rate of $10 \mathrm{~L} \mathrm{~min}^{-1}$. The CCN activity of the soot particles was determined using a continuous-flow Cloud Condensation Nuclei Counter (CCNC) from Droplet Measurement Technologies (DMT; Roberts and Nenes, 2005). As size-selected particles were investigated, the $\mathrm{CCN}$ activity was investigated by exclusively modulating the SS in the range from $0.2 \%$ to $1.4 \%$. An additional data point at a SS of $1.6 \%$ was acquired in CBK experiments. With an acquisition duration of 6-10 min at each set point, the sampling interval for a full scan was approximately $66 \mathrm{~min}$.

\subsection{Experimental procedure and experimental conditions}

The experimental procedure and therefore the data that can be acquired differ from experiments conducted in OFRs and batch reactors. As an example, a typical data set of an $\mathrm{O}_{3}$ experiment is displayed in Fig. 2 (experiment no. 3 in Table 1 , no denuder, $5 \% \mathrm{RH}$ ). The $\mathrm{CCN}$ activity is presented as colored crosses (right bottom axis), the particle number concentration as a black line (left bottom axis), the $\mathrm{O}_{3}$ con- 


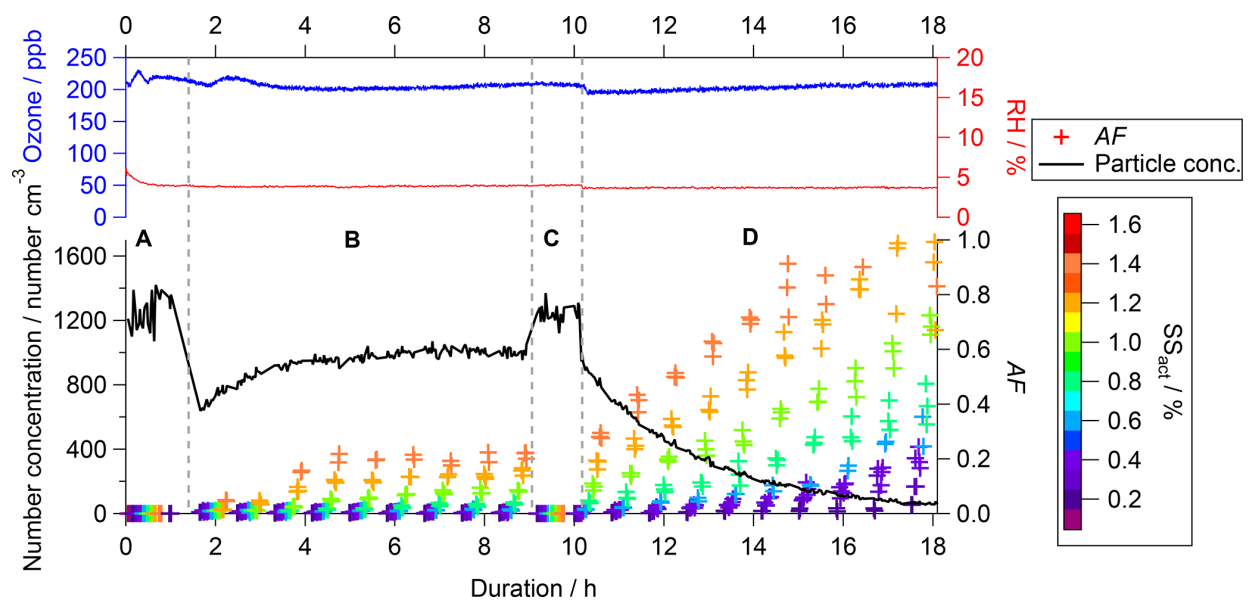

Figure 2. Example of data of the CCN activity (colored crosses, right bottom axis), particle number concentration (black line, left bottom axis), $\mathrm{O}_{3}$ concentration (blue line, left top axis), and $\mathrm{RH}$ (red line, right top axis) as a function of experimental duration (bottom axis). The crosses presenting the $\mathrm{CCN}$ activated fraction (AF) are color-coded by the SS as indicated in the color scale on the right. The labels A (bypass), B (filling), C (bypass), and D (flushing) indicate specific periods within the experiment.

centration as a blue line (left top axis), and RH as a red line (right top axis), all as a function of experimental duration (bottom axis).

While the experiment was conducted for about $18 \mathrm{~h}$ in total, individual time frames can be distinguished and are indicated by the capital letters A to D - the four modes of operation - in Fig. 2. Before the start of each experiment we ensured that the aerosol chamber was particle-free, i.e., a particle concentration of $<1 \mathrm{~cm}^{-3}$ at the CPC downstream of the aerosol chamber. Then the aerosol chamber was filled with the size-selected particles at a flow rate of $23 \mathrm{~L} \mathrm{~min}^{-1}$. During the first hour, a subset of the aerosol stream (approx. $4 \mathrm{~L} \mathrm{~min}^{-1}$ ) bypassed the aerosol chamber for the determination of the baseline characteristics of the aerosol. This period is indicated by the letter A (bypass). Data acquisition from the bypass was completed after completion of one full SS scan in the CCNC. From then on, the sample was extracted from the aerosol chamber, while the filling of the aerosol chamber continued. This period is indicated by the letter B (filling). Due to running the aerosol chamber in CSTR mode, a dynamic equilibrium was established within the aerosol chamber after a certain time. Once sufficient data of the aerosol in that stage were acquired (at least 3 full scans with the CCNC), another bypass sampling period was started. This period is indicated by the letter $\mathrm{C}$ (bypass) in Fig. 2. Data of this period were used to ensure that no changes in the particle production caused changes in the particle properties since the start of the experiment. Similarly to the procedure in period $\mathrm{A}$, one full SS scan in the CCNC was executed before this sampling period was completed by returning to sampling from behind the aerosol chamber. Simultaneous to changing the sampling extraction location, the supply of fresh soot particles into the aerosol chamber was stopped. The particle-containing inlet flow was replaced by particle- and VOC-free compressed air. This period is indicated by the letter D (flushing).

The experimental procedure is reflected by the change in particle number concentration (black line, left bottom axis) presented in Fig. 2. The values present the concentration within the sampling line just in front of the measurement instruments. Therefore, values recorded within bypass periods $\mathrm{A}$ and $\mathrm{C}$ present the particle number concentration in the bypass section and values recorded within periods $\mathrm{B}$ and $\mathrm{C}$ present the particle concentration in the reaction chamber. At the beginning of period $\mathrm{B}$, an increase in particle number concentration is recorded asymptotically, approaching a plateau in the dynamic equilibrium. The particle loss rate within the aerosol chamber is significantly higher compared to the bypass section; therefore, the particle number concentration within the plateau is lower compared to periods A and C. Throughout the flushing period $\mathrm{D}$, an exponential decay of the particle number concentration is recorded in accordance with theoretical expectations as no fresh particles are supplied to the aerosol chamber. The experimental conditions within this period can be considered similar to standard batch experiments. Monitoring and active control of the particle number concentration, $\mathrm{RH}$, and temperature within the feedin flow as well as $\mathrm{O}_{3}$ concentration, $\mathrm{RH}$, and pressure within the aerosol chamber ensured consistent experimental conditions within the aerosol chamber. The $\mathrm{O}_{3}$ concentration (blue line) as well as RH (red line) within the aerosol chamber are shown in the top panel in Fig. 2, illustrating the constant conditions throughout the duration of the entire experiment. The experimental conditions investigated within this study span a multidimensional space as $\mathrm{O}_{3}(0$ or $200 \mathrm{ppb}), \mathrm{RH}$ ( $5 \%$ or $75 \%$ ), and gas-phase VOC contents (sample denuded or undenuded) were varied. Each of these settings was repeated 


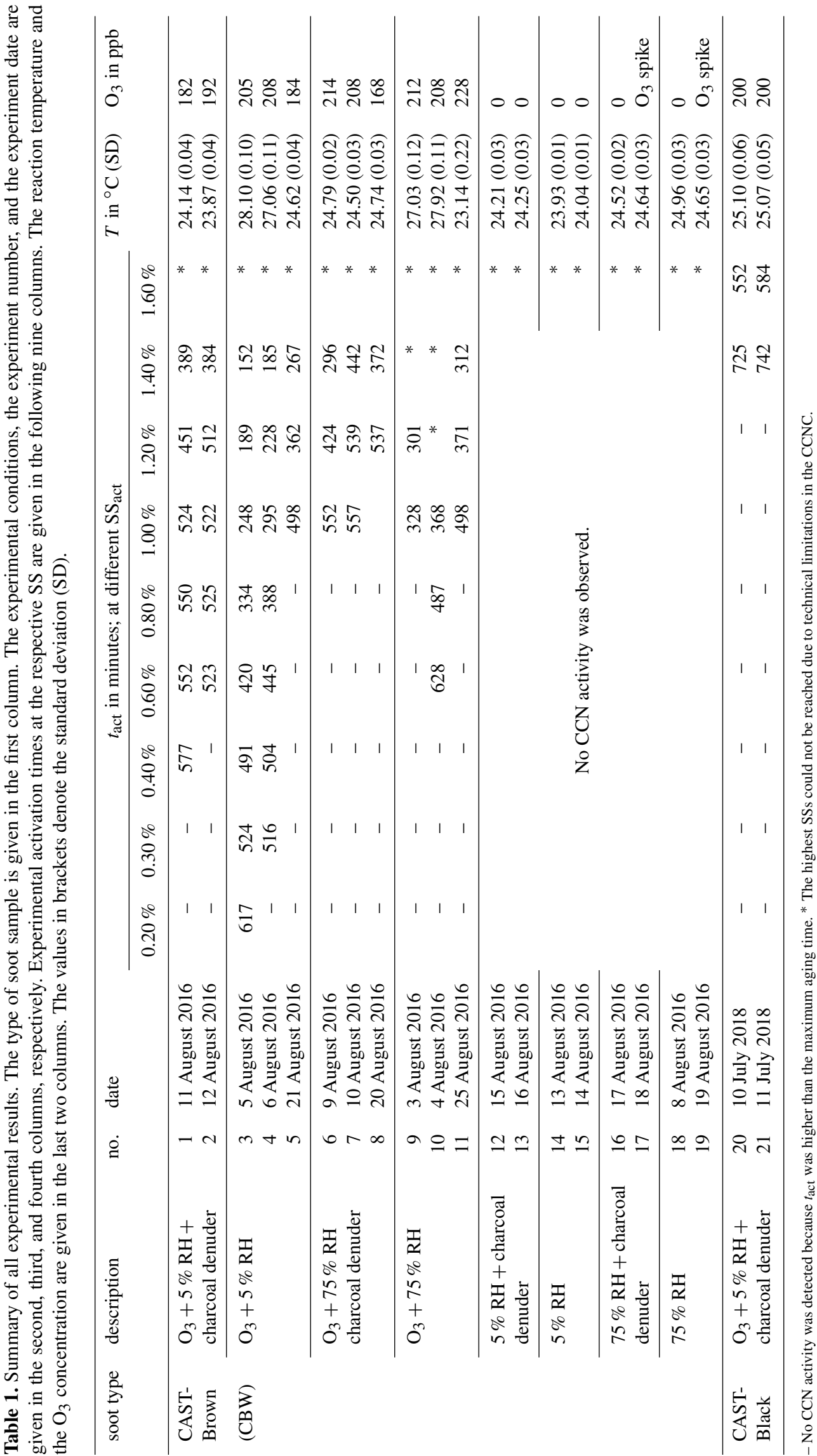


at least twice. A summary of the experimental conditions is shown in Table 1.

The experiments conducted in summer 2016 were executed at room temperature, which varied from day to day. During the experiments in summer 2018, the temperature in the aerosol chamber was actively controlled and held at $25^{\circ} \mathrm{C}$ in addition to the room temperature being controlled and maintained at $23^{\circ} \mathrm{C}$. The chamber temperature ensured constant reaction conditions and the room temperature ensured constant operating conditions of the measurement instruments.

\section{Data analysis}

\subsection{CSTR mode versus batch mode}

As can be seen in Fig. 2, the transformation of fresh soot particles at an atmospherically relevant $\mathrm{O}_{3}$ concentration requires multiple hours of reaction time before $\mathrm{CCN}$ activity of the particles can be detected (after $\sim 2 \mathrm{~h}$ ). In batch-mode operation, a reaction volume is first filled with the sample aerosol as quickly as possible to achieve high homogeneity of the sample. After the desired starting concentration is achieved, further addition of the sample aerosol is stopped and the aging is initiated, e.g., by addition of the oxidant. This point in time is generally referred to as $t=0$ in such experiments. Analysis of the sample takes place while the reaction volume is flushed with sample-free gas. The aerosol chamber available at ETH Zurich has a volume of $\sim 3 \mathrm{~m}^{3}$. Therefore, it was not possible to achieve sampling times of up to $12 \mathrm{~h}$ at the flow rates required by the suite of instruments deployed if the aerosol chamber was operated in batch mode. With the aim of performing aging experiments at atmospherically relevant oxidant concentrations and allowing for atmospherically representative aging durations, the aerosol chamber was operated in CSTR mode. As mentioned previously, this mode of operation is characterized by a continuous addition of fresh aerosol simultaneous to a continuous extraction of the sample while the reaction conditions (e.g., oxidant concentration) are kept constant in the reaction volume.

While the entire aerosol is uniformly aged in batch experiments, the aerosol within a CSTR setup consists of a homogeneous mixture of differently aged aerosol particles. The continuous extraction of particle sample taking place concurrently to the addition of fresh particles causes fresh and old particles of varying residence times to be present simultaneously. Supported by the active mixing of the fan, the extracted sample consists of a homogeneous mixture of the particles in the aerosol chamber. The distribution of the particles in terms of their residence time within the aerosol chamber is well defined as it solely depends on the characteristics (e.g., volume) and operating conditions (e.g., flow rates) of the aerosol chamber operated in CSTR mode. The variability in residence times is referred to as residence time distribution (RTD) under ideal conditions and particle age distribution (PAD) under real conditions, as will be discussed in the following section. A more detailed description of the experimental approach used here can be found in Friebel and Mensah (2019).

\subsection{Activated fraction}

The CCN activity of the soot particles is presented as an activated fraction $(\mathrm{AF})$, which is calculated by dividing the number of activated soot particles detected by the CCNC by the total number of particles entering the CCNC. The total number of particles (black line in Fig. 2) is calculated by integrating the size distribution data of the SMPS downstream of the aerosol chamber. Independent of the SS, AF is 0 in both bypass periods ( $\mathrm{A}$ and $\mathrm{C}$ ), indicating no $\mathrm{CCN}$ activity of the unaged soot particles. This finding is consistent throughout all of the experiments performed.

At the beginning of the filling phase (B), AF is still 0 even though the sample is taken from the aerosol chamber volume. Measured AF increases only after a certain time threshold and reaches a constant level similar to the evolution of the particle number concentration. The plateau phase indicates that the conditions within the aerosol chamber have reached steady state. The point in time that AF deviates from 0 as well as the AF value in the plateau phase are dependent on the SS. The time it takes for AF to deviate from 0 is shorter, and AF reaches higher values with increasing SS.

When the experimental settings are switched to flushing (phase D), i.e., no fresh particles are supplied to the aerosol chamber any longer, a steep increase in AF can be observed, while the particle number concentration decreases exponentially. In theory, a maximum AF of 1 should be reached at all SS levels if sufficient experimental aging time was permitted. In the case of the experiment shown in Fig. 2, the experimental duration is sufficient to allow for an AF of 1 at SS of $1.4 \%$ and $1.2 \%$ only. Due to the CSTR concept, the evolution of AF over time is significantly different from experiments conducted in batch-mode aerosol chambers; therefore, a different data analysis concept is required.

\subsection{Activation time $t_{\text {act }}$}

Generally, the critical supersaturation $\left(\mathrm{SS}_{\text {crit }}\right)$ is reported from batch experiments to present the CCN activity of the particles. The $\mathrm{SS}_{\text {crit }}$ is defined as the $\mathrm{SS}$ where an AF of 0.5 is reached at a specific time after the start of the experiment. This parameter cannot be extracted directly from CSTR data as presented herein. Instead, the new parameter, the activation time $\left(t_{\text {act }}\right)$, will be used as a reference parameter, as has been introduced by Friebel and Mensah (2019). Although $t_{\mathrm{act}}$ and its corresponding activation supersaturation $\left(\mathrm{SS}_{\mathrm{act}}\right)$ are not identical to the $\mathrm{SS}_{\text {crit }}$, after a defined aging time, both data sets are comparable. 
While the transformation caused by the $\mathrm{O}_{3}$ oxidation can be considered a continuous process, the change in $\mathrm{CCN}$ activity of an individual soot particle at a defined SS is discontinuous and can be referred to as a non-gradual transition or a transition within a binary system as a particle is either inactive or active. In this context, $t_{\text {act }}$ represents the minimum aging time a single soot particle requires to cross a certain transformation threshold. The $t_{\text {act }}$ concept is valid for any transformation process involving a threshold. In the specific case presented herein, this process corresponds to a change in CCN activity. As can be seen in Table $1, t_{\text {act }}$ is dependent on the SS. The higher the SS, the shorter $t_{\text {act }}$. In other words, the higher the SS, the less transformation and therefore the less time is needed to cause $\mathrm{CCN}$ activation of a particle. The AF can, therefore, be defined as the fraction of particles that is older than $t_{\text {act }}$. Assuming ideal conditions, $t_{\text {act }}$ in steady state can be calculated following Eq. (1), with $\tau_{\text {CSTR }}$ being the hydrodynamic residence time which is defined as the ratio of the volume of the CSTR ( $V_{\mathrm{CSTR}}$ ) to the total flow rate through the volume $(\dot{V})$ (Friebel and Mensah, 2019).

$$
\begin{aligned}
& t_{\mathrm{act}}=-\ln (\mathrm{AF}) \cdot \tau_{\mathrm{CSTR}} \\
& \tau_{\mathrm{CSTR}}=\frac{V_{\mathrm{CSTR}}}{\dot{V}}
\end{aligned}
$$

\subsection{Particle losses}

Knowledge of the PAD inside the aerosol chamber is required for the extraction of $t_{\text {act }}$. In case particle losses are negligible, the PAD within the aerosol chamber is identical to the RTD of the particles as shown in the equation below (Eq. 3).

$\operatorname{RTD}(t)=e^{\frac{-t}{\tau \operatorname{CSTR}}}$

If particle losses occur, the PAD deviates from the RTD. As apparent by the reduced particle number concentration within the aerosol chamber in steady state compared to the bypass measurements, significant particle losses occurred in the aerosol chamber. In fact, there were two processes occurring simultaneously which cause a reduction in particle number concentration. First, the particle loss to any surface within the aerosol chamber, e.g., the aerosol chamber walls. Since this loss process can be described by a first-order loss kinetic, the loss rate ( $\left.k_{\text {loss }}\right)$ is directly proportional to the particle number concentration. Second, the particle removal due to sample extraction $\left(k_{\mathrm{CSTR}}\right)$, which can be considered a loss process as well. Since both processes follow the same kinetic, they can be combined by introducing the effective particle loss rate $k_{\text {age }}$ and its reciprocal, the particle lifetime $\tau_{\text {age }}$. To obtain $k_{\text {age }}$ for the two first-order particle loss processes, the individual loss rate constants have to be summed up as shown in Eq. (4) below. $k_{\text {age }}=k_{\text {CSTR }}+k_{\text {loss }}=\frac{1}{\tau_{\text {CSTR }}}+\frac{1}{\tau_{\text {loss }}}=\frac{1}{\tau_{\text {age }}}$

$\operatorname{PAD}(t)=e^{\frac{-t}{\tau_{\mathrm{gge}}}}$

Here, the particle wall loss rate constant is $k_{\text {loss }}$. The particle flush rate constant $\left(k_{\mathrm{CSTR}}\right)$ is the inverse of the hydrodynamic residence time $\tau_{\mathrm{CSTR}}$. The PAD can finally be calculated by substituting $\tau_{\mathrm{CSTR}}$ in Eq. (1) by the real particle lifetime ( $\left.\tau_{\text {age }}\right)$ from Eq. (4), leading to Eq. (5) as shown above. The individual loss rates were determined in every single experiment according to the following procedure. The decay in particle number concentration recorded during flushing (period D) was defined as the total loss rate $k_{\text {age }}$. Assuming ideality of the setup, the experimental flush rate is expected to be equal to the theoretical flush rate $\left(k_{\mathrm{CSTR}}\right)$, which can be calculated based on the flow rates (Eq. 2). Therefore, the difference between the experimental value and the theoretical value corresponds to the wall loss rate $k_{\text {loss }}$.

During the first campaign (summer 2016) when the majority of CBW experiments were performed, $\tau_{\text {age }}$ ranged from 96 to $102 \mathrm{~min}$ and $\tau_{\text {loss }}$ from 500 to $800 \mathrm{~min}$. During the second campaign (summer 2018) when the CBK experiments were performed, $\tau_{\text {age }}$ ranged from 100 to $108 \mathrm{~min}$. The increased particle lifetime was a result of a reduced wall loss rate and therefore an increased $\tau_{\text {loss }}$ ranging from 1000 to $2000 \mathrm{~min}$. We attribute this pronounced change in wall loss rate within the aerosol chamber to the fact that the aluminum fan was gold-plated prior to the second campaign.

\section{Results}

\subsection{CCN activity}

Following the discussion in the previous section, the real $t_{\text {act }}$ can be calculated by replacing the ideal hydrodynamic residence time $\left(\tau_{\mathrm{CSTR}}\right)$ in Eq. (1) with the real particle lifetime $\left(\tau_{\text {age }}\right)$ from Eq. (4), leading to Eq. (6) shown below.

$t_{\text {act }}=-\ln (\mathrm{AF}) \cdot \tau_{\text {age }}$

Table 1 provides an overview of all the experiments performed, including the various experimental conditions employed. Significant CCN activation was observed only in experiments with an $\mathrm{O}_{3}$ concentration of $\sim 200 \mathrm{ppb}$. In contrast to the impact of $\mathrm{O}_{3}$, neither elevated humidity conditions nor VOC denuding had an effect detectable with the instrumentation deployed.

In Fig. 3, the activation time ( $t_{\mathrm{act}}$, left axis) as a function of the activation supersaturations ( $\mathrm{SS}_{\mathrm{act}}$, bottom axis) is presented for the same experiment as shown in Fig. $2(100 \mathrm{~nm}$ CBW, $200 \mathrm{ppb} \mathrm{O}_{3}$, RH $5 \%$, no denuding; experiment no. 3 in Table 1). The right axis shows the cumulative $\mathrm{O}_{3}$ exposure in molec $\mathrm{s} \mathrm{cm}^{-3}$, which is the product of the $\mathrm{O}_{3}$ concentration 


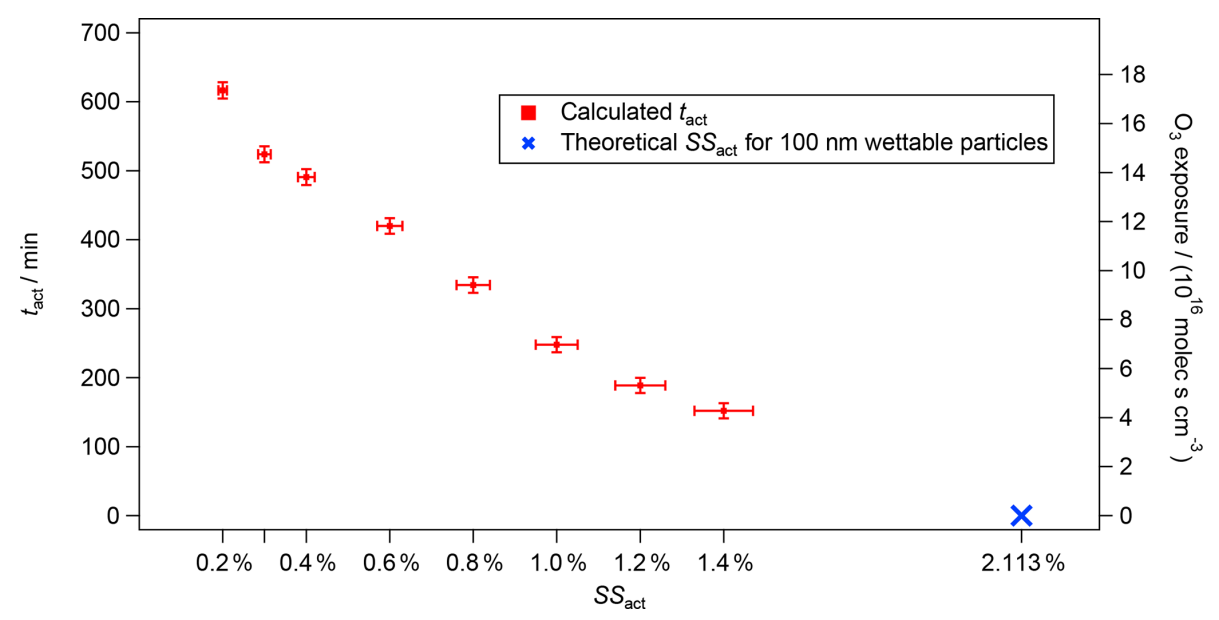

Figure 3. $t_{\text {act }}$ (left axis) and $\mathrm{O}_{3}$ exposure (right axis) versus theoretical (blue cross) and experimental (red markers) $\mathrm{SS}_{\text {act }}$ for the experiment from 5 August 2016 with $\mathrm{CBW}$ and $\mathrm{O}_{3}(200 \mathrm{ppb})$. The vertical bars represent the total error of $t_{\text {act }}$ of \pm 12 min, which originates from the instrumental errors of the CPC and CCNC. The horizontal bars show the $5 \%$ uncertainty in the SS of the CCNC (Rose et al., 2008).

and the exposure time. In our case, the exposure time corresponds to $t_{\text {act }}$. While an activation time of 152 min was determined at an $\mathrm{SS}_{\text {act }}$ of $1.4 \%$, the activation time was more than 3 times higher at an atmospherically relevant $\mathrm{SS}_{\text {act }}$ of $0.3 \%$ (524 min). An activation time of $617 \mathrm{~min}(>10 \mathrm{~h})$ was determined at an $\mathrm{SS}_{\mathrm{act}}$ of $0.2 \%$, highlighting the capability of achieving atmospherically relevant aging durations within an aerosol chamber run in CSTR mode. The activation times are calculated from the AF in steady state according to Eq. (6). The vertical error bars represent an instrumental uncertainty of \pm 12 min calculated by error propagation from the instrumental uncertainties of the CCNC and CPC. The horizontal error bars represent a $5 \%$ uncertainty in the SS inside the CCNC following the recommendations of Rose et al. (2008). Details on the error calculation are presented in Friebel and Mensah (2019).

As can be seen in Fig. 2, the increase in AF from zero appears later with decreasing SS. Similarly, lower AFs are determined for lower SS in steady state. Both aspects correspond to an increase in activation time with decreasing SS. In other words, the modification caused by $\mathrm{O}_{3}$ oxidation needs a longer time to allow for CCN activation at lower SSs.

As mentioned previously, no CCN activation could be determined without exposure to $\mathrm{O}_{3}$. Nevertheless, the $\mathrm{SS}_{\text {act }}$ and $t_{\text {act }}$ for $\mathrm{CBW}$ particles without $\mathrm{O}_{3}$ exposure can be estimated using kappa-Köhler theory (Petters and Kreidenweis, 2007). A spherical particle with a diameter of $100 \mathrm{~nm}$ that is non-hygroscopic (kappa $=0$ ) but fully wettable (contact angle $=0^{\circ}$ ) should activate at a SS of $2.1 \%$ (blue cross in Fig. 3). As can be seen, this theoretical data point aligns well with the experimental results. Overall, an almost linear decrease in $t_{\text {act }}$ was determined with increasing $\mathrm{SS}_{\mathrm{act}}$, as can be seen in Fig. 3. However, this is a theoretical approach, as there is no scientific evidence that would support a linear correlation between oxidation with $\mathrm{O}_{3}$ and $\mathrm{SS}_{\text {act }}$. Furthermore, it is unclear whether the soot used here is fully wettable or only partially wettable (contact angle $>0^{\circ}$ ), which would require a higher $\mathrm{SS}_{\mathrm{act}}$ at $t_{\mathrm{act}}=0 \mathrm{~min}$.

In all experiments with an $\mathrm{O}_{3}$ concentration of $200 \mathrm{ppb}$, the same trend of decreasing $t_{\text {act }}$ with increasing $\mathrm{SS}_{\text {act }}$ was observed independent of soot type, RH and VOC conditions. Despite the similarity in the trend, the individual values of $t_{\text {act }}$ at the same $\mathrm{SS}_{\mathrm{act}}$ change by up to a factor of 2 between experiments of the same soot type and at the same experimental conditions in terms of $\mathrm{O}_{3}$ concentration, $\mathrm{RH}$ and VOC concentration. For example, looking at $t_{\text {act }}$ for CBW particles at $200 \mathrm{ppb} \mathrm{O}_{3}, 5 \% \mathrm{RH}$, without denuding, and at an $\mathrm{SS}_{\text {act }}$ of $1.4 \%$ leads to a value of $152 \mathrm{~min}$ for experiment no. 3 and $267 \mathrm{~min}$ for experiment no. 5. These two values differ by a factor of 1.8. This deviation is significantly higher than the instrumental uncertainty of \pm 12 min discussed above. Further analysis of the experimental conditions in summer 2016 and additional test experiments indicate that the average reaction temperature inside the aerosol chamber had a significant impact on the activation time. With increasing reaction temperature, shorter $t_{\mathrm{act}} \mathrm{s}$ were determined. Because attempts to control the room temperature by air conditioning in summer 2016 were not sufficient to keep the reaction temperature stable, the temperature of the aerosol chamber itself was actively controlled in the experiments performed in summer 2018.

\subsection{CAST black}

During the second measurement campaign in summer 2018 a second soot type (CAST black; CBK) was investigated. The particles of this soot type are characterized by a significantly reduced OC content compared to $\mathrm{CBW}$ particles as presented in Table A1. CBK particles were exposed to $200 \mathrm{ppb} \mathrm{O}_{3}$ at $\mathrm{RH}$ of $5 \%$ with a charcoal denuder in line. As no impact of 
$\mathrm{RH}$ and VOC could be determined in the campaign in summer 2016, these parameters were kept constant in all CBK experiments in summer 2018. Nevertheless, the experimental setup was improved by implementing a direct temperature control of the chamber (see Sect. 2.5) and by reducing particle losses (see Sect. 3.4).

A significant difference in $\mathrm{CCN}$ activity upon $\mathrm{O}_{3}$ exposure was determined between the two soot types - CBW and CBK. As can be seen in Table 1, CBK particles show much lower CCN activity than $\mathrm{CBW}$ particles. CBK particles had to be oxidized for 725 to $742 \mathrm{~min}$ in order to show $\mathrm{CCN}$ activity at an $\mathrm{SS}_{\text {act }}$ of $1.4 \%$, which corresponds to an increase in $t_{\text {act }}$ by a factor of 2 to 4 times compared to CBW particles (experiment no. 20 and no. 21 versus no. 1 and no. 2 in Table 1). Considering similar minimum aging durations $/ t_{\mathrm{act}} \mathrm{s}$, CBW particles activate at an $\mathrm{SS}_{\text {act }}$ of $0.4 \%$ after 552 and 523 min (no. 1 and no. 2), while $\mathrm{CBK}$ particles require an $\mathrm{SS}_{\text {act }}$ of $1.6 \%$ for activation after 552 and $584 \mathrm{~min}$ (no. 20 and no. 21), respectively. Overall, no CCN activity of CBK particles could be detected at atmospherically relevant SS (0.3\%-0.8\% ; Pruppacher and Klett, 2010) within the maximum aging time of up to $12 \mathrm{~h}$.

\section{$4.3 \quad O_{3}$ spike experiments}

For experiments no. 17 and no. 19, soot particles were not exposed to $\mathrm{O}_{3}$ while the aerosol chamber was filled. Only after switching to the flushing mode was the $\mathrm{O}_{3}$ concentration ramped to $200 \mathrm{ppb}$ within approximately $30 \mathrm{~min}$. Once this concentration threshold was reached, no further $\mathrm{O}_{3}$ was added. The $\mathrm{O}_{3}$ concentration decayed exponentially, reaching a value of $50 \mathrm{ppb}$ within $120 \mathrm{~min}$ after the $\mathrm{O}_{3}$ supply to the aerosol chamber was switched off. Despite the temporary exposure to $\mathrm{O}_{3}$, no $\mathrm{CCN}$ activity at any $\mathrm{SS}$ could be detected within the remaining experimental duration of $6 \mathrm{~h}$. However, an increase in the particle mean diameter of $3 \mathrm{~nm}$ was detected while the $\mathrm{O}_{3}$ was added to the chamber.

\section{Discussion}

In an attempt to attribute the change in CCN activity to the heterogeneous oxidation with $\mathrm{O}_{3}$, we investigated various parameters. These parameters include particle size, reaction temperature, relative humidity, and VOC content of the sample. The particle size was determined by DMA measurements. Size distribution measurements of the particles before and after aging in the aerosol chamber revealed no substantial restructuring such as compaction of the particles. On the contrary, a slight growth upon $\mathrm{O}_{3}$ exposure was detected in the range of $3 \mathrm{~nm}$. Such growth of particles has already been reported by Fendel et al. (1995) for metal and spark discharge graphite particles and by Kotzick et al. (1997) for spark discharge graphite particles. A detailed analysis of this aspect is beyond the scope of this paper.
Experiments performed during the measurement campaign in summer 2016 were executed at room temperature without active temperature control of the aerosol chamber. Despite an air conditioning unit being installed, the difference between the coldest and warmest average daily temperatures measured throughout the campaign was greater than $5 \mathrm{~K}$. Referring to the results of two $\mathrm{CBW}$ experiments executed at the same conditions (200 ppb $\mathrm{O}_{3}, 5 \% \mathrm{RH}$, without denuder; experiment nos. 3 to 5 in Table 1), it can be seen that a decrease in the average chamber temperature is associated with an increase in activation time. Such temperature dependency is in accordance with the expected impact of temperature on the reaction speed following the van't Hoff rule. It is known from model simulations and experimental studies that the $\mathrm{O}_{3}$ oxidation of PAHs and organic molecules with $\mathrm{C}=\mathrm{C}$ double bonds require an activation energy of 40 to $80 \mathrm{~kJ} \mathrm{~mol}^{-1}$ (Berkemeier et al., 2016; Lee et al., 2009; Pöschl et al., 2001; Stephens et al., 1989). Even though many different compounds can be found on soot surfaces, PAHs are considered to be a good reference compound (Slowik et al., 2004). A temperature change by $5 \mathrm{~K}$ would change the reaction speed and therefore $t_{\text {act }}$ by a factor of 2 . The deviations in $t_{\text {act }}$ determined experimentally are within the same order of magnitude as the theoretical calculations, supporting the presumed impact of reaction temperature.

Investigation of the $\mathrm{RH}$ conditions revealed neither a short-term nor long-term effect within the range 5\%-75\%. Changes in the particle morphology could be considered a short-term effect. Contrary to the impact of $\mathrm{O}_{3}$, no significant change in the particle diameter could be detected upon exposure of the particles to elevated RH conditions. Overall, our findings are supported by Mahrt et al. (2018), who showed that the water uptake on $\mathrm{CBW}$ and $\mathrm{CBK}$ particles does not exceed the adsorption of one monolayer at RH below $90 \%$. Long-term exposure of the particles to elevated RH conditions showed no impact on the CCN activity even after up to $12 \mathrm{~h}$, which is independent of the soot type investigated within this study.

Homogeneous $\mathrm{O}_{3}$ oxidation of VOCs can lead to semivolatile reaction products, which in turn can condense onto pre-existing particles and thereby modify the particle's CCN activity (Wittbom et al., 2014). Because the VOC concentration within the aerosol chamber could not be determined directly, the impact of VOCs emitted by the miniCAST was evaluated by implementing a charcoal denuder in the experimental setup. No impact on CCN activity or particle size could be determined for experiments with and without the denuder in line.

\section{CCN activity}

In Fig. 3 the $t_{\text {act }}$ as a function of $\mathrm{SS}_{\text {act }}$ is presented. As can be seen, increasing $\mathrm{SS}_{\text {act }}$ are associated with decreasing $t_{\text {act }} \mathrm{s}$. The uncertainty in the determination of $t_{\text {act }}$ is $\pm 12 \mathrm{~min}$ and originates from the instrumental errors of the CPC and 
CCNC as reported by Friebel and Mensah (2019). Therefore, relative uncertainties in $t_{\text {act }}$ and the calculated $\mathrm{O}_{3}$ exposure are below $10 \%$. Compared to the uncertainties reported for the $\mathrm{OH}$ exposure from different OFRs which are on the order of a factor of 5 (Lambe et al., 2011; Simonen et al., 2017), the uncertainties for the approach used here are significantly smaller.

While the distinct mechanism that leads to the significant change in CCN activity of oxidized soot (e.g., inverse Kelvin effect, formation of soluble or surface-active compounds) cannot be identified, we can rule out that the change is due to a growth of the particle diameter. The average diameter increase (CBW: $+3 \mathrm{~nm}$; $\mathrm{CBK}:+1.5 \mathrm{~nm}$ ) is too small to have a decisive impact on the $\mathrm{CCN}$ activity. Furthermore, the growth of the diameter occurs on a timescale of max. $30 \mathrm{~min}$ and is therefore much faster than the change in CCN activity which occurs over a timescale of multiple hours.

Overall, the soot particles show more pronounced CCN activation after exposure to $\mathrm{O}_{3}$ than has been reported previously in the literature. It should be mentioned that this assertion is qualitative, because the particle sizes and particle compositions vary across the different studies. Nevertheless, the cumulative $\mathrm{O}_{3}$ exposure, the product of the $\mathrm{O}_{3}$ concentration and the exposure time, can be taken as a metric for comparison. On that basis, $100 \mathrm{~nm}$ diameter CBK particles in our study $\left(\mathrm{SS}_{\text {act }}=1.6 \%\right.$ after $4.9 \times 10^{16} \mathrm{molec} \mathrm{s} \mathrm{cm}^{-3}$ $\mathrm{O}_{3}$ exposure) show CCN activity within the same order of magnitude as $150 \mathrm{~nm}$ kerosene diffusion flame soot particles investigated by Grimonprez et al. (2018) $\left(\mathrm{SS}_{\text {crit }}=1.4 \%\right.$ after $10 \times 10^{16}$ molec s cm ${ }^{-3} \mathrm{O}_{3}$ exposure) and as $222 \mathrm{~nm}$ ethylene pre-mix flame soot particles $\left(\mathrm{SS}_{\text {crit }}=1.5 \%\right.$ after $5 \times 10^{16}$ molec s cm ${ }^{-3} \mathrm{O}_{3}$ exposure; Lambe et al., 2015).

The differences could be attributed to the different chemical compositions of the soot particles as well as the different experimental setups, but indisputable statements cannot be made on the basis of the data currently available. Experiments by Lambe et al. (2015) were performed at an $\mathrm{O}_{3}$ concentration of up to $20 \mathrm{ppm}$ and an exposure time of $100 \mathrm{~s}$. In contrast to that, the approach presented herein allows for atmospherically relevant oxidant concentrations $(200 \mathrm{ppb})$ and exposure times (up to $12 \mathrm{~h}$ ). Note that the comparison approach in terms of the cumulative $\mathrm{O}_{3}$ exposure performed here is valid only if the reaction speed is directly proportional to the $\mathrm{O}_{3}$ concentration, i.e., follows a first-order reaction kinetic. The validity of this assumption cannot be verified on the basis of the data presented herein.

The differing activation times of CBW and CBK particles investigated in the same experimental setup indicate an impact of the chemical composition. $\mathrm{O}_{3}$ exposures higher by a factor of 2 to 4 are required to cause the same level of activation for CBK particles compared to CBW particles of the same size and experimental conditions. In view of the abundance of soot particles in the atmosphere, the increase in CCN activity of CBW and CBK particles due to heterogeneous oxidation of soot particles can be considered atmo- spherically relevant. A linear extrapolation to atmospheric $\mathrm{O}_{3}$ background concentration levels of 20 to $45 \mathrm{ppb}$ (Hough and Derwent, 1990; Vingarzan, 2004) shows that CBW and CBK particles would become $\mathrm{CCN}$-active at $0.3 \% \mathrm{SS}$ after 2 to 4 and 4 to $16 \mathrm{~d}$, respectively. These values lie within the range of the average atmospheric lifetime of 1 week (Textor et al., 2006) and indicate that this aging pathway could be a significant source of $\mathrm{CCN}$-active soot particles within the atmosphere.

\section{Atmospheric relevance}

Similarly to in a CSTR aerosol chamber, particles are constantly emitted into the atmosphere as well as constantly removed from the atmosphere except in the case of plume events. As a result, a mixture of particles at different aging stages is present in the atmosphere. From this perspective, the atmosphere can be approximated to be a CSTR in steady state. This approximation indicates that CSTR data are at least as suitable for parameterizations in global climate model data obtained from other experimental setups. We performed three experiments with the ECHAM6.3-HAM2.3 global aerosol-climate model (Neubauer et al., 2019; Tegen et al., 2019) to evaluate whether the change in CCN activity of soot particles due to heterogeneous $\mathrm{O}_{3}$ oxidation has an impact on the cloud droplet number concentration (CDNC) and therefore on cloud properties from a global perspective. The size distribution of atmospheric aerosol particles in ECHAM6.3-HAM2.3 is described by seven log-normal modes (four internally mixed modes and three externally mixed modes), the particle number concentration, and the mass mixing ratio of up to five aerosol components (sulfate, $\mathrm{BC}$, particulate organic matter (POM), sea salt, mineral dust). While the structure of the size distribution is prescribed, the particle number concentration and the mixing ratio of each component are computed prognostically for each mode (for details, see Tegen et al., 2019). All BC emissions (fossil fuel, bio-fuel, biomass burning) and the POM emissions from fossil fuel are emitted into the externally mixed Aitken mode. Sixty-five percent of POM emissions from bio-fuel, biomass burning and biogenic secondary organic aerosols are emitted into the internally mixed modes, and $35 \%$ of these emissions are considered insoluble and emitted into the externally mixed Aitken mode (Zhang et al., 2012). In the standard setting of ECHAM6.3-HAM2.3, which was used for the reference (REF) experiment, only aerosol particles in the internally mixed modes can serve as CCN. Their activation is further dependent on their size and hygroscopicity. The activation of aerosol particles to cloud droplets occurs following a Köhler theory-based parameterization of Abdul-Razzak and Ghan (2000) (for details, see Stier, 2016). Our REF experiment is almost identical to the E63H23-10CC experiment presented in Neubauer et al. (2019), with the exception of three differences. First, while the modeling experiment sim- 
ulates a period of 20 years, the aerosol emissions are based on the year 2008 for all years within our simulation. Second, 31 hybrid-sigma vertical levels were used in our simulations versus 47 in Neubauer et al. (2019), as our focus is on the troposphere. Sigma hybrid means that the levels close to the surface follow the topography (sigma), while the levels at higher altitude follow the pressure evolution. Third, the activation parameterization was updated as in the standard version the calculation of the average solubility of the individual modes yielded artificially low values (Neubauer et al., 2019). Two sensitivity modeling experiments were performed that were identical to the REF experiment except that in these sensitivity experiments the REF experiment was extended by allowing BC and POM particles in the externally mixed Aitken mode to activate to cloud droplets using a parameterization developed based on the results from the CSTR aging experiments. Details of this parameterization will be described briefly in the next section, and further details can be found in the Appendix (Sect. B).

\subsection{Parameterization of experimental results}

Following the scheme of Abdul-Razzak et al. (1998), parameter B in Eqs. (B1) and (B3) therein entails the solubility of the aerosol particles in the model and is calculated from the van't Hoff factor $v$ and the osmotic coefficient $\varphi$. These parameters $(v$ and $\varphi)$ are not directly available from our measurements, but their product can be calculated taking the particle diameter $(d=100 \mathrm{~nm})$ and the activation supersaturation $\left(\mathrm{SS}_{\mathrm{act}}=0.3 \%\right)$ of the particles of interest $(\mathrm{BC}$ and POM particles in the externally mixed Aitken mode) into account as shown in Eqs. (B1)-(B3) in Appendix B. While the product of $v$ and $\varphi$ is kept constant at all time steps and for all grid boxes, the fraction of $\mathrm{CCN}$-active $\mathrm{BC}$ and $\mathrm{POM}$ particles in the externally mixed Aitken mode per grid box $\left(X_{\mathrm{CCN}}\right)$ is calculated for each grid box and time step individually. According to the definition of $t_{\mathrm{act}}, X_{\mathrm{CCN}}$ is equal to the fraction of these specific particles that are older than $t_{\text {act }}$. In both sensitivity experiments, individual reference activation times ( $\left.t_{\text {act, ref }}\right)$ representative of CBW and CBK particles were chosen for BC and POM particles in the externally mixed Aitken mode. $t_{\text {act, ref }}$ is defined as the minimum aging time after which the particles show $\mathrm{CCN}$ activity at $0.3 \% \mathrm{SS}$ and an $\mathrm{O}_{3}$ concentration of $200 \mathrm{ppb}$. In the first case $t_{\text {act, ref }}$ is equal to $10 \mathrm{~h}$, which is derived from the experimentally determined $t_{\text {act }}$ for CBW. In the second case $t_{\text {act,ref }}$ is equal to $50 \mathrm{~h}$, which is set based on an extrapolation from experimentally determined $t_{\text {act }}$ values for CBK. The effective $t_{\text {act }}$ is calculated from $t_{\text {act, ref }}$ and the $\mathrm{O}_{3}$ concentration in the grid box at each time step assuming a first-order reaction kinetics with respect to $\mathrm{O}_{3}$ in accordance with Friedman et al. (2011), Lambe et al. (2015) and Grimonprez et al. (2018) as shown below in Eq. (7). More information can be found in Appendix B. $t_{\mathrm{act}}=t_{\mathrm{act}, \mathrm{ref}} \cdot \frac{200 \mathrm{ppb}}{\left[\mathrm{O}_{3}\right]}$

Adapting Eq. (3), which describes the residence time distribution in a CSTR, allows for the estimation of the particle age distribution in the atmosphere as presented in Eq. (8). The ideal mean particle lifetime $\left(\tau_{\mathrm{CSTR}}\right)$ is replaced by the average atmospheric lifetime $\left(\tau_{\text {atm }}\right)$ of soot particles, i.e., $7 \mathrm{~d}$ according to Textor et al. (2006).

$\operatorname{PAD}_{\mathrm{atm}}(t)=e^{\frac{-t}{\tau_{\mathrm{atm}}}}$

Integration of the atmospheric $\operatorname{PAD}_{\text {atm }}(t)$ from $t=t_{\text {act }}$ to $t=$ infinity (Eq. 9) yields $X_{\mathrm{CCN}}$, the fraction of CCN-active $\mathrm{BC}$ and POM particles in the externally mixed Aitken mode.

$X_{\mathrm{CCN}}=\int_{t=t_{\mathrm{act}}}^{t=\infty} \operatorname{PAD}_{\mathrm{atm}}(t) \mathrm{d} t=e^{\frac{-t_{\mathrm{act}}}{\tau_{\mathrm{atm}}}}$

Please note that the increase in the soot particle's hygroscopicity due to oxidation with $\mathrm{O}_{3}$ increases the soot particle removal rate from the atmosphere, e.g., due to a higher wet-deposition rate. As a result, the average atmospheric lifetime of soot particles decreases. However, the reduction of the soot particle lifetime was below $2 \%$ in both scenarios. Since this lifetime reduction is statistically not significant, its impact on the CCN burden and CDNC was not considered within this study.

\subsection{Results - modeling}

The results of the REF experiment and the sensitivity experiments are presented in Fig. 4. While the top row presents the 20 -year mean vertically integrated cloud condensation nuclei (CCN burden; left, a) and cloud droplet number concentration (CDNC burden; right, $b$ ) in the REF experiment, the two other rows present the change in these parameters, taking the effect of the heterogeneous $\mathrm{O}_{3}$ oxidation of soot particles into account. The middle row (Fig. 4c, d) presents changes in the $\mathrm{CCN}$ burden and CDNC burden assuming a reference activation time of $10 \mathrm{~h}$, which can be considered representative of the activation behavior of brown carbon particles. Changes due to the contribution of black carbon particles are presented in the bottom row (Fig. 4e, f) with $t_{\text {act, ref }}=50 \mathrm{~h}$ as a representative value. To allow for a better perceptibility of the important features within the figures, hatching indicates statistically non-significant differences at the $95 \%$ significance level. A two-tailed unpaired Student's $t$ test is computed for each model grid box from annual mean values (20 for each experiment). The false discovery rate of the statistical significance is controlled following Wilks (2016).

Figure $4 \mathrm{c}$ and e present the change in $\mathrm{CCN}$ burden due to consideration of $\mathrm{BC}$ and POM particles in the externally 

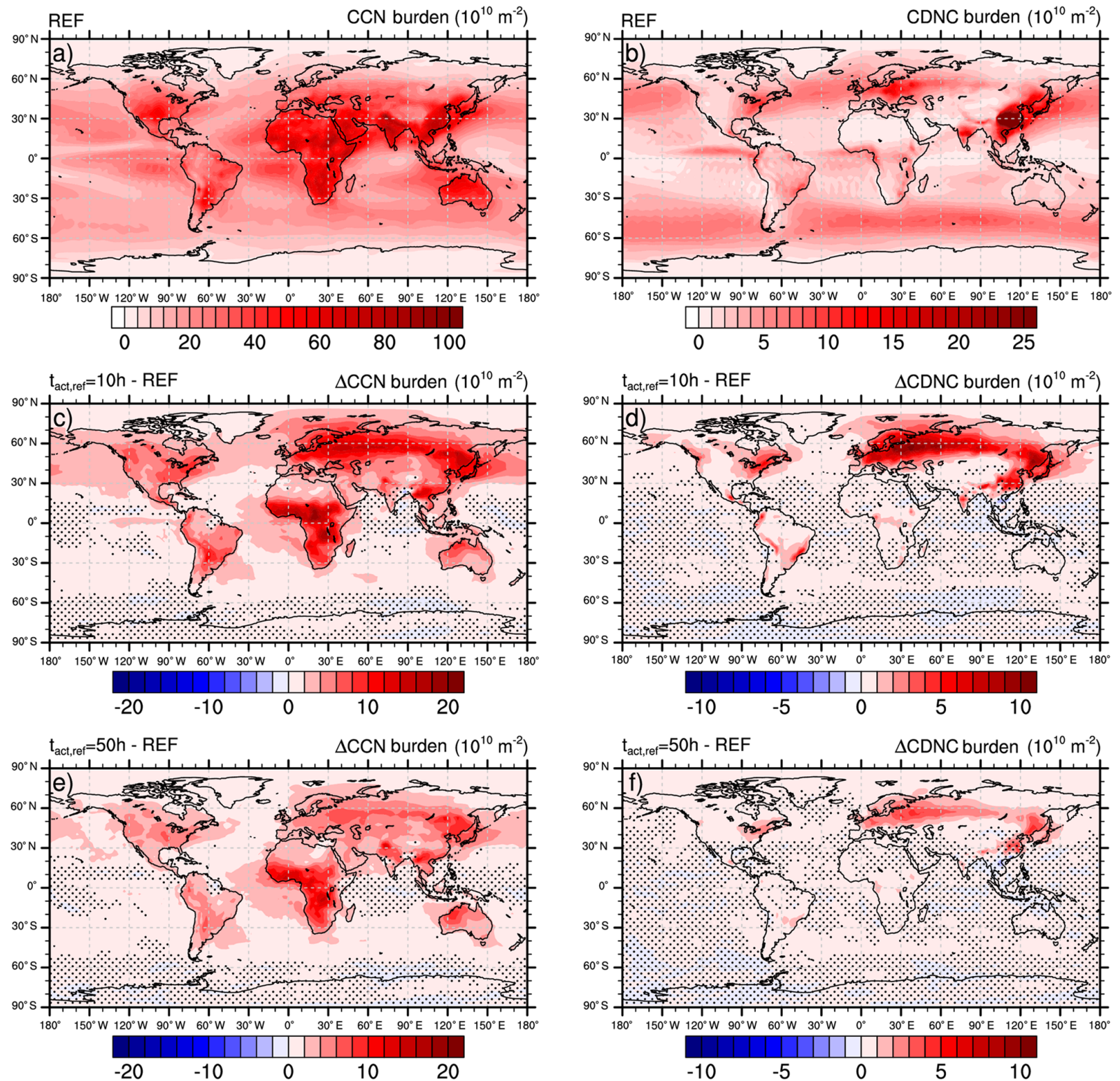

Figure 4. 20-year mean vertically integrated burden of cloud condensation nuclei (CCN; a, c, e) and cloud droplet number concentration $(\mathrm{CDNC} ; \mathbf{b}, \mathbf{d}, \mathbf{f})$, respectively) of the reference simulation (REF; $\mathbf{a}, \mathbf{b})$ and the change due to heterogeneous $\mathrm{O}_{3}$ oxidation of soot particles for two reference activation times $t_{\text {act,ref }}=10 \mathrm{~h}(\mathbf{c}, \mathbf{d})$ and $t_{\mathrm{act}, \mathrm{ref}}=50 \mathrm{~h}(\mathbf{e}, \mathbf{f})$. Blue colors indicate a reduction and red colors indicate an increase in the respective parameter. Note that, for better perceptibility of the important features, hatching indicates statistically nonsignificant differences $(<95 \%)$.

mixed Aitken mode after heterogeneous $\mathrm{O}_{3}$ oxidation. Independent of $t_{\text {act,ref, }}$, the strongest increase in $\mathrm{CCN}$ burden can be seen in the northern latitudes as well as in the tropics, namely over the sub-Saharan African continent. Overall the increase is more pronounced in the case of $t_{\text {act, ref }}=10 \mathrm{~h}$, which is representative of the transition behavior of brown carbon as determined within our experiments with CBW particles. Taking CBW particles into account, the global mean CCN burden increases from $22.4 \times 10^{10} \mathrm{~m}^{-2}$ in REF to $25.3 \times 10^{10} \mathrm{~m}^{-2}$ (Table 2). This increase of $12.7 \%$ is sta- tistically significant. At this $t_{\text {act,ref }}$, the maximal regional increase can be determined in the latitudes north of $60^{\circ}$, with a relative increase of more than $70 \%$. Taking the transition behavior of black carbon particles into account $\left(t_{\text {act, ref }}=50 \mathrm{~h}\right)$, which has been determined by the investigation of CBK particles, the global mean $\mathrm{CCN}$ burden is determined to be $24.6 \times 10^{10} \mathrm{~m}^{-2}$. This increase of $9.7 \%$ is statistically significant but 3 percentage points less than in the case of $t_{\text {act, ref }}=10 \mathrm{~h}$. Investigating the regional impact, the relative increase still maximizes in the latitudes north of $60^{\circ}$ but 
Table 2. CCN mean burden of the three simulations globally averaged and averaged over different regions in the Northern Hemisphere as well as the change due to consideration of $\mathrm{CCN}$-active $\mathrm{BC}$ and POM particles in the externally mixed Aitken mode after heterogeneous $\mathrm{O}_{3}$ oxidation.

\begin{tabular}{lrrr|rr}
\hline Region & \multicolumn{3}{c|}{ CCN burden $/\left(10^{10} \mathrm{~m}^{-2}\right)$} & \multicolumn{2}{c}{$\Delta$ CCN burden/\% } \\
\cline { 2 - 6 } & REF & $t_{\text {act, ref }}=10 \mathrm{~h}$ & $t_{\text {act, ref }}=50 \mathrm{~h}$ & $t_{\text {act }, \text { ref }}=10 \mathrm{~h}$ & $t_{\text {act, ref }}=50 \mathrm{~h}$ \\
\hline global & 22.4 & 25.3 & 24.6 & 12.7 & 9.7 \\
$>=60^{\circ} \mathrm{N}$ & 5.3 & 9.1 & 7.2 & 71.5 & 36.0 \\
$>=50^{\circ} \mathrm{N}$ & 9.4 & 14.3 & 12.0 & 52.4 & 27.9 \\
$>=40^{\circ} \mathrm{N}$ & 15.5 & 20.6 & 18.6 & 33.1 & 19.9 \\
\hline
\end{tabular}

Table 3. CDNC mean burden of the three simulations globally averaged and averaged over different regions in the Northern Hemisphere as well as the change due to consideration of $\mathrm{CCN}$-active $\mathrm{BC}$ and POM particles in the externally mixed Aitken mode after heterogeneous $\mathrm{O}_{3}$ oxidation.

\begin{tabular}{lrrr|rr}
\hline Region & \multicolumn{2}{c|}{ CDNC burden $/\left(10^{10} \mathrm{~m}^{-2}\right)$} & \multicolumn{2}{c}{$\Delta$ CDNC burden/\% } \\
\cline { 2 - 6 } & REF & $t_{\text {act, ref }}=10 \mathrm{~h}$ & $t_{\text {act, ref }}=50 \mathrm{~h}$ & $t_{\text {act, ref }}=10 \mathrm{~h}$ & $t_{\text {act, ref }}=50 \mathrm{~h}$ \\
\hline global & 3.2 & 3.8 & 3.5 & 17.8 & 8.9 \\
$>=60^{\circ} \mathrm{N}$ & 1.5 & 3.0 & 2.0 & 93.0 & 30.3 \\
$>=50^{\circ} \mathrm{N}$ & 2.8 & 4.8 & 3.6 & 73.3 & 27.1 \\
$>=40^{\circ} \mathrm{N}$ & 3.7 & 5.6 & 4.4 & 52.8 & 21.0 \\
\hline
\end{tabular}

is about half as strong as in the case of $t_{\text {act,ref }}=10 \mathrm{~h}$. Regional changes in $\mathrm{CCN}$ burden are pronounced where either the emissions or atmospheric burden of BC and POM are large (e.g., tropics) or where $\mathrm{CCN}$ concentrations are relatively low (e.g., central to northern Europe and Asia). We hypothesize that in regions where many $\mathrm{CCN}$ are available in the internally mixed modes, the additional $\mathrm{CCN}$ in the externally mixed Aitken mode compete with the CCN from the internally mixed modes for the available water vapor. This competition is also considered in the parameterization of Abdul-Razzak and Ghan (2000). As a result of this competition the annual mean values of $\mathrm{CCN}$ show the largest differences from the REF experiment in regions where the emissions of BC and POM are large (not shown) and CCN concentrations are relatively low in the REF simulation (see Figs. 4 and S1 in the Supplement).

Similarly to the changes in CCN burden, the strongest increases in CDNC can be found over land in the Northern Hemisphere. However, over the tropics the increase in CDNC is much lower than the increase in the $\mathrm{CCN}$ burden. The difference is caused by the higher abundance of stratiform liquid clouds at mid latitudes compared to the tropics, which is indicated by the higher CDNC burden at mid latitudes (Fig. 4b). Please note that ECHAM6.3-HAM2.3 accounts for CDNC from detrained cloud water of convective clouds, but otherwise the convective cloud parameterization does not consider CDNC (Neubauer et al., 2019). Therefore, our simulations could underestimate the impact of heterogeneous ozone oxidation of soot particles on CDNC, in particular where convective clouds are common like in the tropics. The largest changes in CDNC occur below about $700 \mathrm{hPa}$, i.e., for lowlevel clouds (Fig. S1). Again, the impact at $t_{\text {act,ref }}=10 \mathrm{~h}$ is much more pronounced than at $t_{\text {act, ref }}=50 \mathrm{~h}$, with a global mean CDNC burden of $3.8 \times 10^{10} \mathrm{~m}^{-2}(+17.8 \%$ compared to $\mathrm{REF})$ and $3.5 \times 10^{10} \mathrm{~m}^{-2}(+8.9 \%$ compared to REF $)$, respectively (Table 3 ). The largest increases in liquid cloud droplets occur around $60^{\circ} \mathrm{N}$ over Europe, Asia and North America, causing almost a doubling $(+93.0 \%)$ in the case of $t_{\text {act,ref }}=10 \mathrm{~h}$ and an increase by more than $30 \%$ in the case of $t_{\mathrm{act}, \mathrm{ref}}=50 \mathrm{~h}$.

\section{Conclusion}

We successfully applied the CSTR approach for the investigation of the change in CCN activity of two soot types. Here we present the results of experiments in which soot particles were exposed to $200 \mathrm{ppb} \mathrm{O}_{3}$ and varying levels of humidity for up to $12 \mathrm{~h}$. The CSTR approach allows for a low particle input concentration (1000 to $1500 \mathrm{~cm}^{-3}$ ) and size selection of particles (e.g., at $100 \mathrm{~nm}$ ).

We show that the heterogeneous $\mathrm{O}_{3}$ oxidation is a process that can make soot particles $\mathrm{CCN}$-active at atmospherically relevant SSs of $0.3 \%$ to $0.8 \%$. The general finding agrees with literature results underlining the applicability of the CSTR approach. Nevertheless, the $\mathrm{SS}_{\text {act }}$ in our experiments is significantly lower at the same $\mathrm{O}_{3}$ exposures compared to results obtained in other experimental setups (Grimonprez et al., 2018; Lambe et al., 2015). The soot rich in OC $(\mathrm{CBW})$ required 2 to 4 times less aging time $\left(t_{\mathrm{act}}=3-\right.$ $6 \mathrm{~h}$ at $\left.1.4 \% \mathrm{SS}_{\mathrm{act}}\right)$ than soot low in $\mathrm{OC}\left(\mathrm{CBK}, t_{\mathrm{act}}=12 \mathrm{~h}\right.$ at 
$1.4 \% \mathrm{SS}_{\text {act }}$ ). In contrast to $\mathrm{O}_{3}$, no effect of $\mathrm{RH}$ (up to $75 \%$ ) or denuding of the gas phase was observed. Instead, we found that temperature fluctuations of $5 \mathrm{~K}$ inside the aerosol chamber have a strong impact on the activation time $t_{\text {act }}$ and were the largest single contributor to the experimental uncertainties.

A test with a global aerosol-climate model, where a firstorder kinetic was assumed, showed that the change in CCN activity of soot particles that are not taken into account in the standard configuration can lead to statistically significant increases in CCN burden and CDNC burden. The strongest increases were observed where the soot burden was large and/or the initial CCN concentration was rather low for both reference activation times investigated. In the case of the CDNC burden it is additionally beneficial if CCN do not have to compete for water vapor and stratiform liquid clouds are frequent.

Both the discrepancy in activation levels between studies using different experimental approaches and the initial $\mathrm{O}_{3}$ adsorption detected by a particle diameter increase within minutes suggest that the underlying reaction mechanism might not be sufficiently well described by assuming firstorder kinetics. Therefore, we suggest performance of tailored experiments with a focus on the effect of different $\mathrm{O}_{3}$ concentrations as well as different temperatures. This might allow for further insight into the reaction kinetics and improvement of the accuracy of extrapolations to atmospheric conditions.
Code and data availability. The data presented in this publication can be downloaded from https://doi.org/10.5281/zenodo.3451267 (Friebel et al., 2019a). The scripts to produce Figs. 4 and S1 can be downloaded from https://doi.org/10.5281/zenodo.3452036 (Friebel et al., 2019b). 


\section{Appendix A: Experimental setup}

Table A1. miniCAST 4200 burner set points used to generate soot aerosol.

\begin{tabular}{lrrrrrrr}
\hline $\begin{array}{l}\text { Soot } \\
\text { type }\end{array}$ & $\begin{array}{r}\text { Propane fuel } \\
\left(\mathrm{L} \mathrm{min}^{-1}\right)\end{array}$ & $\begin{array}{r}\mathrm{N}_{2} \text { mixing } \\
\left(\mathrm{L} \mathrm{min}^{-1}\right)\end{array}$ & $\begin{array}{r}\text { Oxidation air } \\
\left(\mathrm{L} \mathrm{min}^{-1}\right)\end{array}$ & $\begin{array}{r}\mathrm{N}_{2} \text { quench } \\
\left(\mathrm{L} \mathrm{min}^{-1}\right)\end{array}$ & $\begin{array}{r}\text { Dilution air } \\
\left(\mathrm{L} \mathrm{min}^{-1}\right)\end{array}$ & $\begin{array}{r}\text { Fuel air } \\
\text { ratio }\end{array}$ & $\begin{array}{r}\mathrm{C}: \mathrm{O} \\
\text { ratio }\end{array}$ \\
\hline $\mathrm{CBW}$ & 0.06 & 0.25 & 1.42 & 7.5 & 20 & 1.03 & 0.31 \\
$\mathrm{CBK}$ & 0.06 & 0.00 & 1.55 & 7.5 & 20 & 0.95 & 0.28 \\
\hline
\end{tabular}




\section{Appendix B: CCN activity of soot in ECHAM6.3-HAM2.3}

Within ECHAM6.3-HAM2.3 seven log-normal modes are defined for the aerosol particle size distribution. The CCN activity of each mode is characterized by component-specific parameters as well as the particle size distribution within each mode according to Abdul-Razzak and Ghan (2000). However, the model does not contain "soot particle" as a category, but contains BC and POM as separate categories. The two categories $\mathrm{BC}$ and POM together represent the properties of soot with a lesser or higher amount of organic material, respectively. Therefore, they are modified together to represent the change in $\mathrm{CCN}$ activity of soot particles due to heterogeneous $\mathrm{O}_{3}$ oxidation.

So far BC and POM particles have been considered to be not CCN-active within ECHAM6.3-HAM2.3, unless they are internally mixed with soluble components such as sulfate. Particles are transferred from the insoluble mode to soluble mode when sufficient sulfuric acid gas condenses on insoluble particles to form a monolayer of coating or by coagulation with soluble particles. The product of the van't Hoff factor $v$ and the osmotic coefficient $\varphi$ describes the solubility of the particles in water. Within ECHAM6.3-HAM2.3, $v \cdot \varphi$ is set to 0 , because $\mathrm{BC}$ and $\mathrm{POM}$ particles are considered to be not $\mathrm{CCN}$-active. However, based on the experimental results we presented, it is possible to calculate a new value of $\nu \cdot \varphi$ for BC and POM particles, which is then used in the model experiments.

With Eqs. (B1), (B2) and (B3) taken from Abdul-Razzak et al. (1998), the product $\nu \cdot \varphi$ can be calculated from a defined particle diameter and its $\mathrm{SS}_{\mathrm{act}}$. The molar mass $\left(M_{\mathrm{BC} / \mathrm{POM}}\right)$ as well as the density $\left(\rho_{\mathrm{BC} / \mathrm{POM}}\right)$ of $\mathrm{BC}$ and POM are the same as in our model experiments and are given along with other constants in Table B1. We choose a $\mathrm{SS}_{\text {act }}$ of $0.3 \%$ and a diameter of $100 \mathrm{~nm}$ as reference values. The corresponding $t_{\text {act,ref }}$ values are used in the computation of $X_{\mathrm{CCN}}$ in the model. To calculate $\nu \cdot \varphi$, the fraction of $\mathrm{CCN}$-active particles $(\epsilon)$ is set to 1 . The values for $v \cdot \varphi$ are then 0.050 and 0.753 for BC and POM, respectively. Note that within the actual model experiments $\epsilon$ is not set to 1 , but it represents the mass fraction of BC or POM in the externally mixed Aitken mode in order to calculate the average SS in the externally mixed Aitken mode.
Table B1. Parameters and constants used for the calculation of the $\mathrm{CCN}$ activity of POM and BC particles.

\begin{tabular}{|c|c|c|}
\hline$\sigma_{\mathrm{a} / \mathrm{w}}$ & $0.072 \mathrm{~J} \mathrm{~m}^{-2}$ & surface tension of water at $25^{\circ} \mathrm{C}$ \\
\hline$M_{\mathrm{W}}$ & $0.018 \mathrm{~kg} \mathrm{~mol}^{-1}$ & molar mass of water \\
\hline$\rho_{\mathrm{W}}$ & $1000 \mathrm{~kg} \mathrm{~m}^{-3}$ & density of water \\
\hline$R$ & $8.314 \mathrm{~J}^{-1} \mathrm{~mol} \mathrm{~K}^{-1}$ & universal gas constant \\
\hline$T$ & $298.15 \mathrm{~K}$ & temperature \\
\hline$d$ & $100 \mathrm{~nm}$ & reference particle diameter \\
\hline SS & $0.3 \%$ & reference SS \\
\hline$\epsilon$ & 1 & mass fraction of soluble material \\
\hline \multicolumn{3}{|c|}{ black carbon (BC) } \\
\hline$M_{\mathrm{BC}}$ & $0.012 \mathrm{~kg} \mathrm{~mol}^{-1}$ & molar mass of black carbon \\
\hline$\rho_{\mathrm{BC}}$ & $2000 \mathrm{~kg} \mathrm{~m}^{-3}$ & density of black carbon \\
\hline \multicolumn{3}{|c|}{ particulate organic matter $(\mathrm{POM})$} \\
\hline$M_{\mathrm{POM}}$ & $0.180 \mathrm{~kg} \mathrm{~mol}^{-1}$ & molar mass of particulate organic matter \\
\hline$\rho_{\mathrm{POM}}$ & $2000 \mathrm{~kg} \mathrm{~m}^{-3}$ & density of particulate organic matter \\
\hline
\end{tabular}

Please note that the treatment of secondary organic aerosol (SOA) is simplified in ECHAM6.3-HAM2.3. During emission the soluble and insoluble fractions of SOA are assumed to condense immediately on the soluble Aitken mode and accumulation and insoluble Aitken mode, respectively. However, He et al. (2016) accounted in their experiments for BC aging by condensation of SOA and found that their chemical aging mechanism still accounted for more than $50 \%$ of the $\mathrm{BC}$ aging rate at high latitudes (polewards of $60^{\circ} \mathrm{N} / \mathrm{S}$ ) and above $900 \mathrm{hPa}$.

$$
\begin{aligned}
& \mathrm{SS}_{\mathrm{act}}=\frac{2}{\sqrt{B}} \cdot\left(\frac{A}{3 \cdot d}\right)^{3 / 2} \\
& A=\frac{4 \cdot \sigma_{\mathrm{a} / \mathrm{w}} \cdot M_{\mathrm{w}}}{R \cdot T \cdot \rho_{\mathrm{w}}} \\
& B=\frac{\nu \cdot \varphi \cdot \epsilon \cdot M_{\mathrm{w}} \cdot \rho_{\mathrm{BC} / \mathrm{POM}}}{M_{\mathrm{BC} / \mathrm{POM}} \cdot \rho_{\mathrm{w}}}
\end{aligned}
$$


Supplement. The supplement related to this article is available online at: https://doi.org/10.5194/acp-19-15545-2019-supplement.

Author contributions. FF and AAM prepared the manuscript with contributions from PL, DN, UL, SDvD and EM. FF, AAM, PL, SDvD and EM designed and conducted the experiments. FF analyzed the experimental data. DN and UL designed and analyzed the model simulations. Figures 1, 2, and 3 were produced by FF and Figs. 4 and $\mathrm{S} 1$ were produced by DN.

Competing interests. The authors declare that they have no conflict of interest.

Acknowledgements. We thank Zamin A. Kanji, Oliver F. Bischof, and Thomas Peter for their valuable discussions and U1rike Lohmann's group for their support.

Financial support. This research has been supported by the Schweizerischer Nationalfonds zur Förderung der Wissenschaftlichen Forschung (grant nos. PZ00P2_161343, IZK0Z2_168324) and the Swiss National Supercomputing Centre (project ID s652).

Review statement. This paper was edited by Ari Laaksonen and reviewed by two anonymous referees.

\section{References}

Abdul-Razzak, H. and Ghan, J.: A parameterization of aerosol activation 2. Multiple aerosol types, J. Geophys. Res., 105, 68376844, https://doi.org/10.1029/1999JD901161, 2000.

Abdul-Razzak, H., Ghan, S., and Rivera-Carpio, C.: A parameterization of aerosol: activation 1. Single aerosol type, J. Geophys. Res., 103, 6123-6131, https://doi.org/10.1029/97JD03735, 1998.

Ackerman, A. S., Toon, O. B., Stevens, D. E., Heymsfield, A. J., Ramanathan, V., and Welton, E. J.: Reduction of Tropical Cloudiness by Soot, Science, 288, 1042-1047, https://doi.org/10.1126/science.288.5468.1042, 2000.

Ammann, M., Pöschl, U., and Rudich, Y.: Effects of reversible adsorption and Langmuir-Hinshelwood surface reactions on gas uptake by atmospheric particles, Phys. Chem. Chem. Phys., 5, 351-356, https://doi.org/10.1039/B208708A, 2003.

Anenberg, S. C., Schwartz, J., Shindell, D., Amann, M., Faluvegi, G., Klimont, Z., Janssens-Maenhout, G., Pozzoli, L., Dingenen, R. Van, Vignati, E., Emberson, L., Muller, N. Z., West, J. J., Williams, M., Demkine, V., Hicks, W. K., Kuylenstierna, J., Raes, F., and Ramanathan, V.: Global Air Quality and Health Co-benefits of Mitigating NearTerm Climate Change through Methane and Black Carbon Emission Controls, Environ. Health Persp., 120, 831-839, https://doi.org/10.1289/ehp.1104301, 2012.
Bedjanian, Y. and Nguyen, M. L.: Kinetics of the reactions of soot surface-bound polycyclic aromatic hydrocarbons with $\mathrm{O}_{3}$, Chemosphere, 79, 387-393, https://doi.org/10.1016/j.chemosphere.2010.02.009, 2010.

Bedjanian, Y., Nguyen, M. L., and Le Bras, G.: Kinetics of the reactions of soot surface-bound polycyclic aromatic hydrocarbons with the $\mathrm{OH}$ radicals, Atmos. Environ., 44, 1754-1760, https://doi.org/10.1016/j.atmosenv.2010.02.007, 2010.

Berkemeier, T., Steimer, S. S., Krieger, U. K., Peter, T., Poschl, U., Ammann, M., and Shiraiwa, M.: Ozone uptake on glassy, semi-solid and liquid organic matter and the role of reactive oxygen intermediates in atmospheric aerosol chemistry, Phys. Chem. Chem. Phys., 18, 12662-12674, https://doi.org/10.1039/c6cp00634e, 2016.

Bescond, A., Yon, J., Ouf, F. X., Ferry, D., Delhaye, D., Gaffié, D., Coppalle, A., and Rozé, C.: Automated determination of aggregate primary particle size distribution by tem image analysis: Application to soot, Aerosol Sci. Tech., 48, 831-841, https://doi.org/10.1080/02786826.2014.932896, 2014.

Bruns, E. A., El Haddad, I., Keller, A., Klein, F., Kumar, N. K., Pieber, S. M., Corbin, J. C., Slowik, J. G., Brune, W. H., Baltensperger, U., and Prévôt, A. S. H.: Inter-comparison of laboratory smog chamber and flow reactor systems on organic aerosol yield and composition, Atmos. Meas. Tech., 8, 23152332, https://doi.org/10.5194/amt-8-2315-2015, 2015.

Burney, J. and Ramanathan, V.: Recent climate and air pollution impacts on Indian agriculture, P. Natl. Acad. Sci. USA, 111, 1631916324, https://doi.org/10.1073/pnas.1317275111, 2014.

Cocker, D. R., Flagan, R. C., and Seinfeld, J. H.: Stateof-the-art chamber facility for studying atmospheric aerosol chemistry, Environ. Sci. Technol., 35, 2594-2601, https://doi.org/10.1021/es0019169, 2001.

Cozic, J., Mertes, S., Verheggen, B., Cziczo, D. J., Gallavardin, S. J., Walter, S., Baltensperger, U., and Weingartner, E.: Black carbon enrichment in atmospheric ice particle residuals observed in lower tropospheric mixed phase clouds, J. Geophys. Res.Atmos., 113, D15209, https://doi.org/10.1029/2007JD009266, 2008.

Dalirian, M., Ylisirniö, A., Buchholz, A., Schlesinger, D., Ström, J., Virtanen, A., and Riipinen, I.: Cloud droplet activation of black carbon particles coated with organic compounds of varying solubility, Atmos. Chem. Phys., 18, 12477-12489, https://doi.org/10.5194/acp-18-12477-2018, 2018.

Durdina, L., Lobo, P., Trueblood, M. B., Black, E. A., Achterberg, S., Hagen, D. E., Brem, B. T., and Wang, J.: Response of real-time black carbon mass instruments to mini-CAST soot, Aerosol Sci. Tech., 50, 906-918, https://doi.org/10.1080/02786826.2016.1204423, 2016.

Fendel, W., Matter, D., Burtscher, H., and Schmidt-Ott, A.: Interaction between Carbon or Iron aerosol particles and Ozone, Atmos. Environ., 29, 967-973, https://doi.org/10.1016/13522310(95)00038-Z, 1995.

Friebel, F. and Mensah, A. A.: Aging aerosol in a well-mixed continuous-flow tank reactor: an introduction of the activation time distribution, Atmos. Meas. Tech., 12, 2647-2663, https://doi.org/10.5194/amt-12-2647-2019, 2019.

Friebel, F., Lobo, P., Neubauer, D., Lohmann, U., Drossaart van Dusseldorp, S., Mühlhofer, E., and Mensah, A. A.: Data for the publication "Impact of Isolated Atmospheric Aging processes 
on the Cloud Condensation Nucleiactivation of Soot Particles" [Data set], Zenodo, https://doi.org/10.5281/zenodo.3451267, 2019a.

Friebel, F., Lobo, P., Neubauer, D., Lohmann, U., Drossaart van Dusseldorp, S., Mühlhofer, E., and Mensah, A. A.: Script for the publication "Impact of Isolated Atmospheric Aging processes on the Cloud Condensation Nucleiactivation of Soot Particles" (Version 1.0), Zenodo, https://doi.org/10.5281/zenodo.3452036, 2019b.

Friedman, B., Kulkarni, G., Beránek, J., Zelenyuk, A., Thornton, J. A., and Cziczo, D. J.: Ice nucleation and droplet formation by bare and coated soot particles, J. Geophys. Res.-Atmos., 116, 111, https://doi.org/10.1029/2011JD015999, 2011.

George, I. J., Vlasenko, A., Slowik, J. G., Broekhuizen, K., and Abbatt, J. P. D.: Heterogeneous oxidation of saturated organic aerosols by hydroxyl radicals: uptake kinetics, condensed-phase products, and particle size change, Atmos. Chem. Phys., 7, 41874201, https://doi.org/10.5194/acp-7-4187-2007, 2007.

Grimonprez, S., Faccinetto, A., Batut, S., Wu, J., Desgroux, P., and Petitprez, D.: Cloud condensation nuclei from the activation with ozone of soot particles sampled from a kerosene diffusion flame, Aerosol Sci. Tech., 52, 814-827, https://doi.org/10.1080/02786826.2018.1472367, 2018.

Haywood, J. and Boucher, O.: Estimates of the direct and indirect radiative forcing due to tropospheric aerosols: A review, Rev. Geophys., 38, 513-543, https://doi.org/10.1029/1999RG000078, 2000.

He, C., Li, Q., Liou, K.-N., Qi, L., Tao, S., and Schwarz, J. P.: Microphysics-based black carbon aging in a global CTM: constraints from HIPPO observations and implications for global black carbon budget, Atmos. Chem. Phys., 16, 3077-3098, https://doi.org/10.5194/acp-16-3077-2016, 2016.

Henning, S., Ziese, M., Kiselev, A., Saathoff, H., Möhler, O., Mentel, T. F., Buchholz, A., Spindler, C., Michaud, V., Monier, M., Sellegri, K., and Stratmann, F.: Hygroscopic growth and droplet activation of soot particles: uncoated, succinic or sulfuric acid coated, Atmos. Chem. Phys., 12, 4525-4537, https://doi.org/10.5194/acp-12-4525-2012, 2012.

Hiranuma, N., Brooks, S. D., Moffet, R. C., Glen, A., Laskin, A., Gilles, M. K., Liu, P., MacDonald, A. M., Strapp, J. W., and McFarquhar, G. M.: Chemical characterization of individual particles and residuals of cloud droplets and ice crystals collected on board research aircraft in the ISDAC 2008 study, J. Geophys. Res.-Atmos., 118, 6564-6579, https://doi.org/10.1002/jgrd.50484, 2013.

Hoose, C., Kristjánsson, J. E., Chen, J.-P., and Hazra, A.: A Classical-Theory-Based Parameterization of Heterogeneous Ice Nucleation by Mineral Dust, Soot, and Biological Particles in a Global Climate Model, J. Atmos. Sci., 67, 2483-2503, https://doi.org/10.1175/2010JAS3425.1, 2010.

Hough, A. M. and Derwent, R. G.: Changes in the global concentration of tropospheric ozone due to human activities, Nature, 344, 645-648, https://doi.org/10.1038/344645a0, 1990.

Ihalainen, M., Tiitta, P., Czech, H., Yli-Pirilä, P., Hartikainen, A., Kortelainen, M., Tissari, J., Stengel, B., Sklorz, M., Suhonen, H., Lamberg, H., Leskinen, A., Kiendler-Scharr, A., Harndorf, H., Zimmermann, R., Jokiniemi, J., and Sippula, O.: A novel high-volume Photochemical Emission Aging flow tube Reactor (PEAR), Aerosol Sci. Tech., 53, 276-294, https://doi.org/10.1080/02786826.2018.1559918, 2019.

IPCC: Climate Change 2013: The Physical Science Basis. Contribution of Working Group I to the Fifth Assessment Report of the Intergovern- mental Panel on Climate Change, edited by: Stocker, T. F., Qin, D., Plattner, G.-K., Tignor, M., Allen, S. K., Boschung, J., Nauels, A., Xia, Y., Bex, V., and Midgley, P. M., Cambridge University Press, Cambridge, UK and New York, NY, USA, 1535 pp., 2013.

Janssen, N. A. H., Hoek, G., Simic-Lawson, M., Fischer, P., van Bree, L., ten Brink, H., Keuken, M., Atkinson, R. W., Anderson, H. R., Brunekreef, B., and Cassee, F. R.: Black carbon as an additional indicator of the adverse health effects of airborne particles compared with $\mathrm{PM}_{10}$ and $\mathrm{PM}_{2.5}$, Environ. Health Persp., 119, 1691-1699, 2011.

Kamm, S., Möhler, O., Naumann, K. H., Saathoff, H., and Schurath, U.: The heterogeneous reaction of ozone with soot aerosol, Atmos. Environ., 33, 4651-4661, https://doi.org/10.1016/S13522310(99)00235-6, 1999.

Kang, E., Root, M. J., Toohey, D. W., and Brune, W. H.: Introducing the concept of Potential Aerosol Mass (PAM), Atmos. Chem. Phys., 7, 5727-5744, https://doi.org/10.5194/acp-7-5727-2007, 2007.

Kanji, Z. A., Welti, A., Chou, C., Stetzer, O., and Lohmann, U.: Laboratory studies of immersion and deposition mode ice nucleation of ozone aged mineral dust particles, Atmos. Chem. Phys., 13, 9097-9118, https://doi.org/10.5194/acp-139097-2013, 2013.

Kanji, Z. A., Ladino, L. A., Wex, H., Boose, Y., BurkertKohn, M., Cziczo, D. J., and Krämer, M.: Overview of Ice Nucleating Particles, Meteorol. Monogr., 58, 1.1-1.33, https://doi.org/10.1175/AMSMONOGRAPHS-D-16-0006.1, 2017.

Keller, A. and Burtscher, H.: A continuous photo-oxidation flow reactor for a defined measurement of the SOA formation potential of wood burning emissions, J. Aerosol Sci., 49, 9-20, https://doi.org/10.1016/j.jaerosci.2012.02.007, 2012.

Khalizov, A. F., Zhang, R., Zhang, D., Xue, H., Pagels, J., and McMurry, P. H.: Formation of highly hygroscopic soot aerosols upon internal mixing with sulfuric acid vapor, J. Geophys. Res.Atmos., 114, D05208, https://doi.org/10.1029/2008JD010595, 2009.

Kim, J., Bauer, H., Dobovičnik, T., Hitzenberger, R., Lottin, D., Ferry, D., and Petzold, A.: Assessing optical properties and refractive index of combustion aerosol particles through combined experimental and modeling studies, Aerosol Sci. Tech., 49, 340 350, https://doi.org/10.1080/02786826.2015.1020996, 2015.

Koehler, K. A., Kreidenweis, S. M., DeMott, P. J., Popovicheva, O. B., Carrico, C. M., Petters, M. D., Kireeva, E. D., Khokhlova, T. D., and Shonija, N. K.: Cloud condensation nuclei and ice nucleation activity of hydrophobic and hydrophilic soot particles, Phys. Chem. Chem. Phys., 11, 79067920, https://doi.org/10.1039/b905334b, 2009.

Köhler, H.: The nucleus in and the growth of hygroscopic droplets, Trans. Faraday Soc., 32, 1152-1161, https://doi.org/10.1039/TF9363201152, 1936.

Kotzick, R., Panne, U., and Niessner, R.: Changes in condensation properties of ultrafine carbon particles subjected 
to oxidation by ozone, J. Aerosol Sci., 28, 725-735, https://doi.org/10.1016/S0021-8502(96)00471-5, 1997.

Kulkarni, G., China, S., Liu, S., Nandasiri, M., Sharma, N., Wilson, J., Aiken, A. C., Chand, D., Laskin, A., Mazzoleni, C., Pekour, M., Shilling, J., Shutthanandan, V., Zelenyuk, A., and Zaveri, R. A.: Ice nucleation activity of diesel soot particles at cirrus relevant temperature conditions: Effects of hydration, secondary organics coating, soot morphology, and coagulation, Geophys. Res. Lett., 43, 3580-3588, https://doi.org/10.1002/2016GL068707, 2016.

Lambe, A. T., Ahern, A. T., Williams, L. R., Slowik, J. G., Wong, J. P. S., Abbatt, J. P. D., Brune, W. H., Ng, N. L., Wright, J. P., Croasdale, D. R., Worsnop, D. R., Davidovits, P., and Onasch, T. B.: Characterization of aerosol photooxidation flow reactors: heterogeneous oxidation, secondary organic aerosol formation and cloud condensation nuclei activity measurements, Atmos. Meas. Tech., 4, 445-461, https://doi.org/10.5194/amt-4445-2011, 2011.

Lambe, A. T., Ahern, A. T., Wright, J. P., Croasdale, D. R., Davidovits, P., and Onasch, T. B.: Oxidative aging and cloud condensation nuclei activation of laboratory combustion soot, J. Aerosol Sci., 79, 31-39, https://doi.org/10.1016/j.jaerosci.2014.10.001, 2015.

Lee, G., Lee, B., Kim, J., and Cho, K.: Ozone Adsorption on Graphene: $\mathrm{Ab}$ Initio Study and Experimental Validation, J. Phys. Chem. C, 113, 14225-14229, https://doi.org/10.1021/jp904321n, 2009.

Lelievre, S., Bedjanian, Y., Pouvesle, N., Delfau, J.-L., Vovelle, C., and Le Bras, G.: Heterogeneous reaction of ozone with hydrocarbon flame soot, Phys. Chem. Chem. Phys., 6, 1181-1191, https://doi.org/10.1039/b316895f, 2004.

Leskinen, A., Yli-Pirilä, P., Kuuspalo, K., Sippula, O., Jalava, P., Hirvonen, M.-R., Jokiniemi, J., Virtanen, A., Komppula, M., and Lehtinen, K. E. J.: Characterization and testing of a new environmental chamber, Atmos. Meas. Tech., 8, 2267-2278, https://doi.org/10.5194/amt-8-2267-2015, 2015.

Levenspiel, O.: Chemical Reaction Engineering, 3rd edn., John Wiley \& Sons, New York, Chichester, Weinheim, Brisbane, Singapore, Toronto, 1999.

Lohmann, U. and Feichter, J.: Global indirect aerosol effects: a review, Atmos. Chem. Phys., 5, 715-737, https://doi.org/10.5194/acp-5-715-2005, 2005.

Mahrt, F., Marcolli, C., David, R. O., Grönquist, P., Barthazy Meier, E. J., Lohmann, U., and Kanji, Z. A.: Ice nucleation abilities of soot particles determined with the Horizontal Ice Nucleation Chamber, Atmos. Chem. Phys., 18, 13363-13392, https://doi.org/10.5194/acp-18-13363-2018, 2018.

Malmborg, V. B., Eriksson, A. C., Török, S., Zhang, Y., Kling, K., Martinsson, J., Fortner, E. C., Gren, L., Kook, S., Onasch, T. B., Bengtsson, P.-E., and Pagels, J.: Relating aerosol mass spectra to composition and nanostructure of soot particles, Carbon N.Y., 142, 535-546, https://doi.org/10.1016/j.carbon.2018.10.072, 2018.

Mamakos, A., Khalek, I., Giannelli, R., and Spears, M.: Characterization of combustion aerosol produced by a mini-CAST and treated in a catalytic stripper, Aerosol Sci. Tech., 47, 927-936, https://doi.org/10.1080/02786826.2013.802762, 2013.

Mao, J., Ren, X., Brune, W. H., Olson, J. R., Crawford, J. H., Fried, A., Huey, L. G., Cohen, R. C., Heikes, B., Singh, H. B., Blake,
D. R., Sachse, G. W., Diskin, G. S., Hall, S. R., and Shetter, R. E.: Airborne measurement of OH reactivity during INTEX-B, Atmos. Chem. Phys., 9, 163-173, https://doi.org/10.5194/acp-9163-2009, 2009.

Marhaba, I., Ferry, D., Laffon, C., Regier, T. Z., Ouf, F. X., and Parent, P.: Aircraft and MiniCAST soot at the nanoscale, Combust. Flame, 204, 278-289, https://doi.org/10.1016/j.combustflame.2019.03.018, 2019.

Maricq, M. M.: Examining the relationship between black carbon and soot in flames and engine exhaust, Aerosol Sci. Tech., 48, 620-629, https://doi.org/10.1080/02786826.2014.904961, 2014.

McCabe, J. and Abbatt, J. P. D.: Heterogeneous loss of gas-phase ozone on n-hexane soot surfaces: Similar kinetics to loss on other chemically unsaturated solid surfaces, J. Phys. Chem. C, 113, 2120-2127, https://doi.org/10.1021/jp806771q, 2009.

McNeill, V. F., Wolfe, G. M., and Thornton, J. A.: The oxidation of oleate in submicron aqueous salt aerosols: Evidence of a surface process, J. Phys. Chem. A, 111, 1073-1083, https://doi.org/10.1021/jp066233f, 2007.

Monks, P. S., Granier, C., Fuzzi, S., Stohl, A., Williams, M. L., Akimoto, H., Amann, M., Baklanov, A., Baltensperger, U., Bey, I., Blake, N., Blake, R. S., Carslaw, K., Cooper, O. R., Dentener, F., Fowler, D., Fragkou, E., Frost, G. J., Generoso, S., Ginoux, P., Grewe, V., Guenther, A., Hansson, H. C., Henne, S., Hjorth, J., Hofzumahaus, A., Huntrieser, H., Isaksen, I. S. A., Jenkin, M. E., Kaiser, J., Kanakidou, M., Klimont, Z., Kulmala, M., Laj, P., Lawrence, M. G., Lee, J. D., Liousse, C., Maione, M., McFiggans, G., Metzger, A., Mieville, A., Moussiopoulos, N., Orlando, J. J., O’Dowd, C. D., Palmer, P. I., Parrish, D. D., Petzold, A., Platt, U., Pöschl, U., Prévôt, A. S. H., Reeves, C. E., Reimann, S., Rudich, Y., Sellegri, K., Steinbrecher, R., Simpson, D., ten Brink, H., Theloke, J., van der Werf, G. R., Vautard, R., Vestreng, V., Vlachokostas, C., and von Glasow, R.: Atmospheric composition change - global and regional air quality, Atmos. Environ., 43, 5268-5350, https://doi.org/10.1016/j.atmosenv.2009.08.021, 2009.

Moore, R. H., Ziemba, L. D., Dutcher, D., Beyersdorf, A. J., Chan, K., Crumeyrolle, S., Raymond, T. M., Thornhill, K. L., Winstead, E. L., and Anderson, B. E.: Mapping the Operation of the Miniature Combustion Aerosol Standard (MiniCAST) Soot Generator, Aerosol Sci. Tech., 48, 467-479, https://doi.org/10.1080/02786826.2014.890694, 2014.

Mueller, L., Jakobi, G., Orasche, J., Karg, E., Sklorz, M., Abbaszade, G., Weggler, B., Jing, L., Schnelle-Kreis, J., and Zimmermann, R.: Online determination of polycyclic aromatic hydrocarbon formation from a flame soot generator, Anal. Bioanal. Chem., 407, 5911-5922, https://doi.org/10.1007/s00216-0158619-0, 2015.

Neubauer, D., Ferrachat, S., Siegenthaler-Le Drian, C., Stier, P., Partridge, D. G., Tegen, I., Bey, I., Stanelle, T., Kokkola, H., and Lohmann, U.: The global aerosol-climate model ECHAM6.3HAM2.3 - Part 2: Cloud evaluation, aerosol radiative forcing, and climate sensitivity, Geosci. Model Dev., 12, 3609-3639, https://doi.org/10.5194/gmd-12-3609-2019, 2019.

Nordin, E. Z., Eriksson, A. C., Roldin, P., Nilsson, P. T., Carlsson, J. E., Kajos, M. K., Hellén, H., Wittbom, C., Rissler, J., Löndahl, J., Swietlicki, E., Svenningsson, B., Bohgard, M., Kulmala, M., Hallquist, M., and Pagels, J. H.: Secondary organic aerosol formation from idling gasoline passenger vehicle emissions investi- 
gated in a smog chamber, Atmos. Chem. Phys., 13, 6101-6116, https://doi.org/10.5194/acp-13-6101-2013, 2013.

Paulsen, D., Dommen, J., Kalberer, M., Prévôt, A. S. H., Richter, R., Sax, M., Steinbacher, M., Weingartner, E., and Baltensperger, U.: Secondary Organic Aerosol Formation by Irradiation of 1,3,5Trimethylbenzene- $\mathrm{NO}_{x}-\mathrm{H}_{2} \mathrm{O}$ in a New Reaction Chamber for Atmospheric Chemistry and Physics, Environ. Sci. Technol., 39, 2668-2678, https://doi.org/10.1021/es0489137, 2005.

Petters, M. D. and Kreidenweis, S. M.: A single parameter representation of hygroscopic growth and cloud condensation nucleus activity, Atmos. Chem. Phys., 7, 1961-1971, https://doi.org/10.5194/acp-7-1961-2007, 2007.

Petzold, A., Ogren, J. A., Fiebig, M., Laj, P., Li, S.-M., Baltensperger, U., Holzer-Popp, T., Kinne, S., Pappalardo, G., Sugimoto, N., Wehrli, C., Wiedensohler, A., and Zhang, X.-Y.: Recommendations for reporting "black carbon" measurements, Atmos. Chem. Phys., 13, 8365-8379, https://doi.org/10.5194/acp13-8365-2013, 2013.

Platt, S. M., El Haddad, I., Zardini, A. A., Clairotte, M., Astorga, C., Wolf, R., Slowik, J. G., Temime-Roussel, B., Marchand, N., Ježek, I., Drinovec, L., Močnik, G., Möhler, O., Richter, R., Barmet, P., Bianchi, F., Baltensperger, U., and Prévôt, A. S. H.: Secondary organic aerosol formation from gasoline vehicle emissions in a new mobile environmental reaction chamber, Atmos. Chem. Phys., 13, 9141-9158, https://doi.org/10.5194/acp13-9141-2013, 2013.

Pöschl, U., Letzel, T., Schauer, C., and Niessner, R.: Interaction of Ozone and Water Vapor with Spark Discharge Soot Aerosol Particles Coated with Benzo[a]pyrene: $\mathrm{O}_{3}$ and $\mathrm{H}_{2} \mathrm{O}$ Adsorption, Benzo[a]pyrene Degradation, and Atmospheric Implications, J. Phys. Chem. A, 105, 4029-4041, https://doi.org/10.1021/jp004137n, 2001.

Presto, A. A., Huff Hartz, K. E., and Donahue, N. M.: Secondary organic aerosol production from terpene ozonolysis. 2. Effect of $\mathrm{NO}_{x}$ concentration, Environ. Sci. Technol., 39, 7046-7054, https://doi.org/10.1021/es050400s, 2005.

Pruppacher, H. R. and Klett, J. D.: Microphysics of clouds and precipitation, Springer, Dordrecht, Heidelberg, London, New York, 2010.

Renbaum, L. H. and Smith, G. D.: Artifacts in measuring aerosol uptake kinetics: the roles of time, concentration and adsorption, Atmos. Chem. Phys., 11, 6881-6893, https://doi.org/10.5194/acp-11-6881-2011, 2011.

Roberts, G. C. and Nenes, A.: A Continuous-Flow Streamwise Thermal-Gradient CCN Chamber for Atmospheric Measurements, Aerosol Sci. Tech., 39, 206-221, https://doi.org/10.1080/027868290913988, 2005.

Rohrer, F., Bohn, B., Brauers, T., Brüning, D., Johnen, F.-J., Wahner, A., and Kleffmann, J.: Characterisation of the photolytic HONO-source in the atmosphere simulation chamber SAPHIR, Atmos. Chem. Phys., 5, 2189-2201, https://doi.org/10.5194/acp5-2189-2005, 2005.

Rose, D., Gunthe, S. S., Mikhailov, E., Frank, G. P., Dusek, U., Andreae, M. O., and Pöschl, U.: Calibration and measurement uncertainties of a continuous-flow cloud condensation nuclei counter (DMT-CCNC): CCN activation of ammonium sulfate and sodium chloride aerosol particles in theory and experiment, Atmos. Chem. Phys., 8, 1153-1179, https://doi.org/10.5194/acp8-1153-2008, 2008.
Savre, J. and Ekman, A. M. L.: A theory-based parameterization for heterogeneous ice nucleation and implications for the simulation of ice processes in atmospheric models, J. Geophys. Res., 120, 4937-4961, https://doi.org/10.1002/2014JD023000, 2015.

Seinfeld, J. H., Bretherton, C., Carslaw, K. S., Coe, H., DeMott, P. J., Dunlea, E. J., Feingold, G., Ghan, S., Guenther, A. B., Kahn, R., Kraucunas, I., Kreidenweis, S. M., Molina, M. J., Nenes, A., Penner, J. E., Prather, K. A., Ramanathan, V., Ramaswamy, V., Rasch, P. J., Ravishankara, A. R., Rosenfeld, D., Stephens, G., and Wood, R.: Improving our fundamental understanding of the role of aerosol-cloud interactions in the climate system, P. Natl. Acad. Sci. USA, 113, 5781-5790, https://doi.org/10.1073/pnas.1514043113, 2016.

Shiraiwa, M., Sosedova, Y., Rouvière, A., Yang, H., Zhang, Y., Abbatt, J. P. D., Ammann, M., and Pöschl, U.: The role of long-lived reactive oxygen intermediates in the reaction of ozone with aerosol particles, Nat. Chem., 3, 291-295, https://doi.org/10.1038/nchem.988, 2011.

Simonen, P., Saukko, E., Karjalainen, P., Timonen, H., Bloss, M., Aakko-Saksa, P., Rönkkö, T., Keskinen, J., and Dal Maso, M.: A new oxidation flow reactor for measuring secondary aerosol formation of rapidly changing emission sources, Atmos. Meas. Tech., 10, 1519-1537, https://doi.org/10.5194/amt10-1519-2017, 2017.

Slowik, J. G., Stainken, K., Davidovits, P., Williams, L. R., Jayne, J. T., Kolb, C. E., Worsnop, D. R., Rudich, Y., DeCarlo, P. F., and Jimenez, J. L.: Particle morphology and density characterization by combined mobility and aerodynamic diameter measurements. Part 2: Application to combustion-generated soot aerosols as a function of fuel equivalence ratio, Aerosol Sci. Tech., 38, 12061222, https://doi.org/10.1080/027868290903916, 2004.

Sorjamaa, R. and Laaksonen, A.: The effect of $\mathrm{H}_{2} \mathrm{O}$ adsorption on cloud drop activation of insoluble particles: a theoretical framework, Atmos. Chem. Phys., 7, 6175-6180, https://doi.org/10.5194/acp-7-6175-2007, 2007.

Stephens, S. L., Birks, J. W., and Calvert, J. G.: Ozone as a sink for atmospheric carbon aerosols today and following nuclear war, Aerosol Sci. Tech., 10, 326-331, https://doi.org/10.1080/02786828908959268, 1989.

Stier, P.: Limitations of passive remote sensing to constrain global cloud condensation nuclei, Atmos. Chem. Phys., 16, 6595-6607, https://doi.org/10.5194/acp-16-6595-2016, 2016.

Tegen, I., Neubauer, D., Ferrachat, S., Siegenthaler-Le Drian, C., Bey, I., Schutgens, N., Stier, P., Watson-Parris, D., Stanelle, T., Schmidt, H., Rast, S., Kokkola, H., Schultz, M., Schroeder, S., Daskalakis, N., Barthel, S., Heinold, B., and Lohmann, U.: The global aerosol-climate model ECHAM6.3-HAM2.3 Part 1: Aerosol evaluation, Geosci. Model Dev., 12, 1643-1677, https://doi.org/10.5194/gmd-12-1643-2019, 2019.

Textor, C., Schulz, M., Guibert, S., Kinne, S., Balkanski, Y., Bauer, S., Berntsen, T., Berglen, T., Boucher, O., Chin, M., Dentener, F., Diehl, T., Easter, R., Feichter, H., Fillmore, D., Ghan, S., Ginoux, P., Gong, S., Grini, A., Hendricks, J., Horowitz, L., Huang, P., Isaksen, I., Iversen, I., Kloster, S., Koch, D., Kirkevåg, A., Kristjansson, J. E., Krol, M., Lauer, A., Lamarque, J. F., Liu, X., Montanaro, V., Myhre, G., Penner, J., Pitari, G., Reddy, S., Seland, Ø., Stier, P., Takemura, T., and Tie, X.: Analysis and quantification of the diversities of aerosol life cycles within AeroCom, Atmos. 
Chem. Phys., 6, 1777-1813, https://doi.org/10.5194/acp-6-17772006, 2006.

Török, S., Malmborg, V. B., Simonsson, J., Eriksson, A., Martinsson, J., Mannazhi, M., Pagels, J., and Bengtsson, P. E.: Investigation of the absorption Ångström exponent and its relation to physicochemical properties for mini-CAST soot, Aerosol Sci. Tech., 52, 757-767, https://doi.org/10.1080/02786826.2018.1457767, 2018.

Twomey, S.: Influence of Pollution on the Shortwave Albedo of Clouds, J. Atmos. Sci., 34, 1149-1152, https://doi.org/10.1175/15200469(1977)034<1149:tiopot>2.0.co;2, 1977.

Vingarzan, R.: A review of surface ozone background levels and trends, Atmos. Environ., 38, 3431-3442, https://doi.org/10.1016/j.atmosenv.2004.03.030, 2004.

WHO: Ambient air pollution: A global assessment of exposure and burden of disease, WHO Document Production Services, Geneva, Switzerland, 2016.

Wilks, D. S.: "The Stippling Shows Statistically Significant Grid Points" How Research Results are Routinely Overstated and Overinterpreted, and What to Do about It, B. Am. Meteorol. Soc., 97, 2263-2274, https://doi.org/10.1175/BAMS-D-15$00267.1,2016$.
Wittbom, C., Eriksson, A. C., Rissler, J., Carlsson, J. E., Roldin, P., Nordin, E. Z., Nilsson, P. T., Swietlicki, E., Pagels, J. H., and Svenningsson, B.: Cloud droplet activity changes of soot aerosol upon smog chamber ageing, Atmos. Chem. Phys., 14, 9831-9854, https://doi.org/10.5194/acp-14-9831-2014, 2014.

Zelenay, V., Monge, M. E., D’Anna, B., George, C., Styler, S. A., Huthwelker, T., and Ammann, M.: Increased steady state uptake of ozone on soot due to UV/Vis radiation, J. Geophys. Res.-Atmos., 116, 1-11, https://doi.org/10.1029/2010JD015500, 2011.

Zhang, K., O’Donnell, D., Kazil, J., Stier, P., Kinne, S., Lohmann, U., Ferrachat, S., Croft, B., Quaas, J., Wan, H., Rast, S., and Feichter, J.: The global aerosol-climate model ECHAM-HAM, version 2: sensitivity to improvements in process representations, Atmos. Chem. Phys., 12, 8911-8949, https://doi.org/10.5194/acp-12-8911-2012, 2012. 